\title{
Diet quality of a population sample from coastal north-east Spain evaluated by a Mediterranean adaptation of the Diet Quality Index (DQI)
}

Isabel Bondia-Pons ${ }^{1,2}$, Jordi Mayneris-Perxachs ${ }^{2}$, Lluís Serra-Majem ${ }^{3}$, Ana I Castellote ${ }^{1,2}$, Abel Mariné ${ }^{1}$ and M Carmen López-Sabater ${ }^{1,2, *}$

${ }^{1}$ Department of Nutrition and Food Science, Reference Centre in Food Technology, Faculty of Pharmacy, University of Barcelona, Av. Joan XXIII s/n, E-08028 Barcelona, Spain: ${ }^{2}$ CIBER Epidemiología y Salud Pública (CIBERESP), Spain: ${ }^{3}$ Department of Clinical Sciences, Center for Health Sciences, University of Las Palmas de Gran Canaria, Las Palmas, Spain

Submitted 3 September 2008: Accepted 29 April 2009: First published online 23 June 2009

\begin{abstract}
Objective: To assess the adherence to the Mediterranean dietary pattern in the population from a coastal region from north-east Spain and its relationship to diseases, applying the Mediterranean Diet Quality Index (M-DQI) validated by the use of several biomarkers.

Design: Cross-sectional nutrition survey.

Setting: Population-based random sample derived from the Catalan Nutrition Survey. Subjects: A total of 621 healthy adults.

Results: The Catalan representative sample presented a mean M-DQI score of 6.6 (sD $2 \cdot 3$, median 7 , range $0-14$ ). The percentage of adherence to the Mediterranean diet was $53 \% ; 10 \%$ of subjects showed high adherence to the Mediterranean diet, while only $2 \%$ were categorized as poorest adherence. The plasma fatty acid profile of the Catalan sample progressed with perfect regularity throughout the index ranges. Both EPA and DHA presented a significant correlation to the M-DQI ( $r=-0.410$ for EPA and -0.360 for DHA). A significant increase in palmitic, oleic and $\alpha$-linolenic acids and a significant decrease in stearic, linoleic and arachidonic acids content were also observed. The mean values for the M-DQI according to the clinical characteristics of the Catalan sample were also calculated.

Conclusions: The M-DQI has been demonstrated a suitable tool for assessment of an individual's nutritional status according to the Mediterranean dietary pattern and for clinical purposes. Although the current diet followed in Catalonia seems to agree with the main characteristics of the Mediterranean diet, the promotion of the Mediterranean pattern should be reinforced in the Catalan population, especially among young people.
\end{abstract}

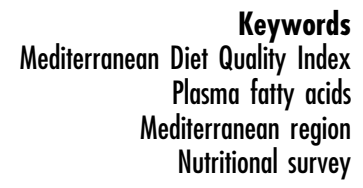

The Mediterranean diet (MD) is an eating pattern characterized by a lifestyle and culture that has been reported to contribute to better health and quality of life for those who adhere to it $^{(1-10)}$. Among its advantages, recent findings from large cohort studies suggest that a high degree of adherence to the MD is associated with a significant reduction in mortality ${ }^{(11-13)}$. Moreover, some intervention studies have demonstrated that adoption of a Mediterranean-type diet reduces several cardiovascular risk factors in subjects at risk or mortality in patients after a first cardiac event ${ }^{(14,15)}$. The main components characterizing this dietary pattern are a high intake of vegetables, fruits, pulses, olive oil and non-refined cereals; a low intake of meat and saturated fats; a moderately high intake of fish (depending on the proximity to the sea); a low-to-moderate intake of dairy products; and a regular but moderate intake of ethanol, primarily in the form of wine and generally during meals ${ }^{(16)}$.

Unfortunately, epidemiological evidence also suggests that dietary patterns in Mediterranean countries are changing rapidly, the main trends being a considerable increase in total energy availability; a notable increased consumption of fat, particularly that of animal origin; and a significant fall in energy availability from carbohydrates $^{(17-19)}$. A departure from the traditional diet might therefore be accompanied by the loss of its protective effects on health ${ }^{(20,21)}$. This hypothesis justifies the extensive work done by several authors in devising 
methods to evaluate the adherence of a population to a Mediterranean diet pattern (MDP). Among these methods, the MD indices are created a priori based on current nutrition knowledge and attempt to make a global, general and qualitative evaluation of the quality of a diet ${ }^{(11,22-24)}$. With this purpose, Gerber and colleagues successfully devised a dietary quality index suitable for evaluation of the $\mathrm{MDP}^{(25)}$. This index, known as the Mediterranean Dietary Quality Index (M-DQI), was performed with the wellknown Diet Quality Index (DQI) based on dietary guidelines developed in the 1990 s by Patterson et al. ${ }^{(26)}$ but incorporating the principal characteristics of the MD. One of the advantages of the M-DQI was its validation with four biological markers in a representative population sample from the French Mediterranean. Biomarkers of intake have largely been used to validate methods to estimate nutrient/ food intake ( $24 \mathrm{~h}$ recall, etc.) and provide a more objective and complementary measure of dietary intake ${ }^{(27)}$. However, such biomarkers have not been used to describe dietary patterns until recently ${ }^{(25,28-36)}$. The M-DQI, applied in representative samples of the French ${ }^{(37)}$ and the Croatian population ${ }^{(38)}$, has not yet been applied to a Spanish Mediterranean population.

Therefore, the aim of the present study was to assess the quality of the diet of Catalonia, a Spanish coastal region, by using the M-DQI. In addition, to better understand and validate the utility of measures of overall diet with nutritional status and health, we compared the M-DQI with several nutritional and clinical biomarkers. The global fatty acid (FA) profile was used as a biomarker of intake. Moreover, established biomarkers of risk of CVD and obesity were also considered.

\section{Subjects and methods}

\section{Subjects}

The subjects were a subgroup of a larger sample (1600 subjects) randomly recruited in Catalonia, a coastal Mediterranean region in north-east Spain, for a crosssectional nutritional survey ${ }^{(39)}$. The sampling technique included stratification according to geographical area and municipality size, age and sex of inhabitants. The participation rate $(65 \%)$ in the present study can be regarded as representative of the adult population in Catalonia. Blood analysis and physiological and anthropometric measurements were obtained from 670 participants in a clinical session after informed consent. Only people who did not under-report their energy intake (ratio of energy intake to $B M R \geq 1 \cdot 14$, according to the Goldberg cutoff $^{(40)}$ ) were considered for analysis. From the resulting 641 Catalans, twenty did not fast for $>12 \mathrm{~h}$ before blood sampling and were excluded. The final sample consisted of 621 subjects, 261 men and 360 women. The study protocol was approved by the regional ethics committee, following the Declaration of Helsinki 1975 standards.

\section{Lifestyle assessment and anthropometry}

Smoking status was assessed by questionnaire during a face-to-face interview. Height $(\mathrm{m})$ weight $(\mathrm{kg})$, waist and hip circumferences $(\mathrm{cm})$, and blood pressure $(\mathrm{mmHg})$ were measured during the clinical session and BMI was calculated as weight (in kilograms) divided by the square of height (in metres). Height was determined using a mobile anthropometer to the nearest millimetre. Body weight (in underwear) was determined to the nearest $100 \mathrm{~g}$ using a digital scale. Waist and hip circumference (WC and HC) were measured using a non-stretchable measuring tape to the nearest centimetre. WC was measured at the navel in men, and midway between the bottom of the ribs and the top of the hip bone in women. $\mathrm{HC}$ was measured at the tip of the hip bone in men, and at the widest point between the hips and the buttocks in women. Blood pressure (BP) was measured twice with a mercury sphygmomanometer after a minimum of $10 \mathrm{~min}$ rest in the seated position.

The cut-off limits proposed by the International Diabetes Federation (2005) for the metabolic syndrome definition in relation to WC, HC, BP and HDL cholesterol (HDL-C) were applied to the present work ${ }^{(41)}$. Only those diseases previously diagnosed and treated by a physician were taken into account for evaluation of the clinical characteristics of the Catalan sample. Furthermore, clinical characteristics pertaining to less than $15 \%$ of the sample were not considered for the analyses.

\section{Nutrition data}

Data on food intake were obtained using an FFQ previously validated ${ }^{(42)}$ and applied to other studies and surveys of the Spanish population ${ }^{(43,44)}$. The FFQ, which asked the subject to recall average use over the past year, consisted of ninety-two items. The FFQ was arranged by food type and meal pattern. Frequency categories were based on the number of times that items were consumed per day, week or month. Daily consumption in grams was determined by dividing the reported intake by the frequency in days. Food values were converted into nutrient values by validated software developed by CESNID (the Centre for Superior Studies in Nutrition and Dietetics), which is based on Spanish tables of food composition ${ }^{(45)}$.

\section{Mediterranean Diet Quality Index}

The M-DQI ${ }^{(25)}$ is an adaptation of the DQI ${ }^{(26)}$ to evaluate the MDP. The M-DQI was intended to describe food consumption in relationship to prevention of chronic diseases. Therefore, it includes variables present in the diet of the Mediterranean population that are assumed to be either healthy or unhealthy. An explanation for the selection of variables has been reported previously ${ }^{(25)}$. A score from 0 to 2 is assigned to each of the seven food/ nutrient groups according to the recommendations, when existing, or otherwise using the population intake tertiles (adjusted by energy) to assign cut-off points (Table 1). 
Table 1 Construction of the Mediterranean Diet Quality Index (M-DQI) score and distribution of component sub-scores among a representative sample $(n 621)$ from Catalonia, north-east Spain

\begin{tabular}{|c|c|c|c|}
\hline \multirow[b]{2}{*}{ M-DQI component } & \multicolumn{3}{|c|}{ Score } \\
\hline & 0 & 1 & 2 \\
\hline SFA ( $\%$ of energy) + & $<10$ & $10-13$ & $>13$ \\
\hline$n$ & 130 & 236 & 255 \\
\hline$\%$ & $21 \cdot 0$ & $38 \cdot 0$ & $41 \cdot 0$ \\
\hline Cholesterol (mg) $†$ & $<300$ & $300-400$ & $>400$ \\
\hline$n$ & 329 & 183 & 109 \\
\hline$\%$ & $53 \cdot 0$ & $29 \cdot 5$ & $17 \cdot 5$ \\
\hline Olive oil $(\mathrm{ml}) \ddagger$ & $>27$ & $16 \cdot 8-27$ & $<16 \cdot 8$ \\
\hline$n$ & 270 & 190 & 161 \\
\hline$\%$ & $43 \cdot 4$ & $30 \cdot 6$ & $26 \cdot 0$ \\
\hline Fish (mg)‡ & $>85$ & $53-85$ & $<53$ \\
\hline$n$ & 211 & 188 & 222 \\
\hline$\%$ & $34 \cdot 0$ & $30 \cdot 3$ & $35 \cdot 7$ \\
\hline Meat $(\mathrm{mg}) \ddagger$ & $<94$ & $94-138$ & $>138$ \\
\hline$n$ & 216 & 214 & 191 \\
\hline$\%$ & $34 \cdot 8$ & $34 \cdot 5$ & $30 \cdot 7$ \\
\hline $\mathrm{F} \& \mathrm{~V}(\mathrm{mg}) \ddagger$ & $>665$ & $445-665$ & $<445$ \\
\hline$n$ & 246 & 204 & 171 \\
\hline$\%$ & $39 \cdot 6$ & $32 \cdot 8$ & $27 \cdot 6$ \\
\hline Cereals (mg) $\ddagger$ & $>179$ & 125-179 & $<125$ \\
\hline$n$ & 201 & 193 & 227 \\
\hline$\%$ & $32 \cdot 4$ & $31 \cdot 1$ & $36 \cdot 5$ \\
\hline
\end{tabular}

$F \& V$, fruit and vegetables.

tScore based on the recommendations of the National Research Council and the American Heart Association.

$\ddagger$ Score based on population intake tertiles derived using intake of Mediterranean components adjusted by energy.

Each group score decreases with higher intake of the corresponding food/nutrient if current guidelines consider it as beneficial for health, while it increases with higher intake if it is considered unhealthy. The group scores were summed to give a total score for the M-DQI, ranging from 0 (maximum adherence to MDP) to 14 (minimum adherence to MDP). The lower the M-DQI value, the healthier is the diet. We classified the scores as follows: good (0-3), medium-good (4-7), medium-poor (8-11) and poor (12-14). For the fish variable, both white and fatty fish were included. The cereal group consisted of all kinds of bread, pasta and breakfast cereals. Both cooked and raw red, yellow and green vegetables and all fresh fruit form the fruit and vegetables ( $\& \& V)$ group. Non-components of the M-DQI also evaluated were alcohol (including beer, wine, liquor and spirits), red wine, pulses, pastries (including all kind of cakes, cookies and sweets), dairy products (including all types of milk and yoghurts, but not cheese) and cheese. The percentage of adherence to the MD was calculated as:

$$
\text { Adherence }(\%)=\left(1-\frac{M-\text { DQI mean }}{14}\right) \times 100 \text {. }
$$

\section{Plasma fatty acid analysis}

Blood samples were collected after the subjects had fasted for $12 \mathrm{~h}$. Plasma was stored at $-80^{\circ} \mathrm{C}$ before being analysed. For analyses, $100 \mu \mathrm{l}$ plasma samples containing $20 \mu \mathrm{g}$ tridecanoic acid (used as the internal standard) were saponified with sodium methylate. Then, samples were esterified with boron trifluoride-methanol at $100^{\circ} \mathrm{C}$. After cooling to $25^{\circ} \mathrm{C}$, fatty acid methyl esters (FAME) were isolated by adding n-hexane. Then, the FA profile was determined by fast-GC ${ }^{(46)}$. Analyses were performed on a Shimadzu GC-2010 gas chromatograph (Kyoto, Japan) equipped with a flame ionization detector and a Shimadzu AOC-20i auto-injector. Separation of FAME was carried out on a capillary column $(10 \mathrm{~m} \times 0 \cdot 1 \mathrm{~mm}$ internal diameter) coated with a SGE-BPX70 cross-linked stationary phase $(70 \%$ cyanopropyl polysilphenylene-siloxane, $0 \cdot 2 \mu \mathrm{m}$ film thickness) from SGE Europe Ltd (Milton Keynes, UK). Results were expressed as relative percentages of total FA.

\section{Statistical analysis}

Analyses were performed with the SPSS statistical software package version $12 \cdot 0$ (SPSS Inc., Chicago, IL, USA). Data are presented as means and standard deviations. Kolmogorov-Smirnov tests were carried out to check normality of variables. ANOVA and the Duncan test (for variables with three or more categories) were used to determine effect comparisons among groups for numeric variables following normality, whereas associations between categorical variables were tested with a $\chi^{2}$ test. Correlations were carried out using the Spearman rank correlation. For all analyses, biomarker concentrations were log-transformed to improve normality and twosided significance was determined at $P<0 \cdot 05$.

\section{Results}

The mean age of the Catalan sample was $47 \cdot 0$ (sD 15.3) years. Of the participants, $15 \%$ were older than 65 years and $17 \%$ were younger than 30 years. Anthropometric and clinical characteristics of the participants are shown in Table 2. Men showed a higher prevalence of risk values for BMI, TAG, glucose and ratio of systolic to diastolic BP (SBP/DBP) than women. Among diagnosed pathologies, only depression/anxiety and rheumatoid arthritis had prevalence higher than $15 \%$. Women suffered more from rheumatoid arthritis, depression/anxiety and thyroid alterations than did men, whereas men suffered more from diabetes and myocardial infarction.

Mean daily consumption, adjusted to energy intake, for each of the seven components of the M-DQI according to sex is shown in Table 3. As expected, the consumption of olive oil, fish, F\&V and cereals increased with perfect regularity with higher adherence to the MD in both genders. Conversely, the consumption of less desirable nutrients and foods decreased regularly with higher adherence to the MD. Higher MDQ-I scores were significantly associated with a lower consumption of pulses only in women, while the opposite trend was found for dairy products but only in men (Table 4). The MDQ-I for all subjects progressed significantly parallel to cheese 
Table 2 Prevalence (expressed as \%) of anthropometric and clinical characteristics according to sex among a representative sample $(n 621)$ from Catalonia, north-east Spain

\begin{tabular}{|c|c|c|c|c|}
\hline & Men $(n 261)$ & Women $(n 360)$ & All $(n$ 621) & $P$ valuet \\
\hline \multicolumn{5}{|c|}{ Anthropometric characteristics } \\
\hline $\mathrm{BMI} \geq$ cut-off $\ddagger$ & $69 \cdot 0$ & $48 \cdot 4$ & $56 \cdot 8$ & $<0.0001$ \\
\hline WC $>$ cut-off $\S$ & $21 \cdot 0$ & $29 \cdot 3$ & $26 \cdot 0$ & 0.056 \\
\hline WHR $>$ cut-offll & $12 \cdot 9$ & $11 \cdot 5$ & $12 \cdot 0$ & $0 \cdot 674$ \\
\hline \multicolumn{5}{|l|}{ CVD risk factors } \\
\hline HDL-C $<$ cut-offtt & $32 \cdot 0$ & $33 \cdot 9$ & $33 \cdot 1$ & $0 \cdot 661$ \\
\hline TAG $>$ cut-off $\ddagger$ & $23 \cdot 0$ & $7 \cdot 9$ & $13 \cdot 9$ & $<0.0001$ \\
\hline Glucose > cut-off $\S$ & $42 \cdot 4$ & $31 \cdot 4$ & $35 \cdot 7$ & 0.011 \\
\hline SBP/DBP $\geq$ cut-off|III & $66 \cdot 5$ & $53 \cdot 2$ & $58 \cdot 5$ & 0.003 \\
\hline Smoker & $34 \cdot 8$ & $30 \cdot 3$ & $32 \cdot 1$ & 0.287 \\
\hline \multicolumn{5}{|l|}{ Diagnosed pathologies } \\
\hline Chronic bronchitis & $8 \cdot 0$ & $5 \cdot 3$ & $6 \cdot 3$ & $0 \cdot 218$ \\
\hline Diabetes & $8 \cdot 5$ & $3 \cdot 3$ & $5 \cdot 4$ & $0 \cdot 011$ \\
\hline Depression/anxiety & $11 \cdot 0$ & $21 \cdot 4$ & $17 \cdot 3$ & 0.003 \\
\hline Embolism/stroke & $1 \cdot 5$ & $1 \cdot 0$ & $1 \cdot 2$ & $0 \cdot 603$ \\
\hline Malignant tumours & $1 \cdot 0$ & $1 \cdot 6$ & $1 \cdot 4$ & 0.545 \\
\hline Thyroid alterations & $0 \cdot 0$ & $4 \cdot 9$ & $3 \cdot 0$ & 0.001 \\
\hline Myocardial infarction & $4 \cdot 5$ & $1 \cdot 3$ & $2 \cdot 6$ & 0.027 \\
\hline Other heart diseases & $6 \cdot 0$ & $6 \cdot 6$ & $6 \cdot 3$ & 0.693 \\
\hline Rheumatoid arthritis & $19 \cdot 0$ & $27 \cdot 6$ & $24 \cdot 2$ & 0.027 \\
\hline Asthma & $5 \cdot 5$ & 3.9 & $4 \cdot 6$ & $0 \cdot 414$ \\
\hline
\end{tabular}

WC, waist circumference; WHR, waist:hip ratio; HDL-C, HDL cholesterol; SBP, systolic blood pressure; DBP, diastolic blood pressure.

$+\chi^{2}$ test.

$\neq$ Cut-off limits: $B M I \geq 25 \mathrm{~kg} / \mathrm{m}^{2}$.

§Cut-off limits: $W C>102 \mathrm{~cm}$ in men; $W C>88 \mathrm{~cm}$ in women.

IICut-off limits: WHR $>1.00$ in men; WHR $>0.90$ in women.

$\uparrow$ Involved in the International Diabetes Federation definition of the metabolic syndrome (2005), with the exception of smokers.

t+Cut-off limits: $\mathrm{HDL}-\mathrm{C}<1.0 \mathrm{mmol} / \mathrm{l}$ in men; $\mathrm{HDL}-\mathrm{C}<1.3 \mathrm{mmol} / \mathrm{l}$ in women.

$¥$ Cut-off limits: TAG $>1 \cdot 7 \mathrm{mmol} / \mathrm{l}$.

$\S \S$ Cut-off limits: fasting plasma glucose $>5.6 \mathrm{mmol} / \mathrm{l}$ or previously diagnosed type 2 diabetes.

IIIICut-off limits: SBP/DBP $\geq 130 / 85 \mathrm{mmHg}$ or treatment of previously diagnosed hypertension.

Table 3 Intake values (adjusted by energy) across the Mediterranean Diet Quality Index (M-DQI) categories according to sex among a representative sample $(n 621)$ from Catalonia, north-east Spain

\begin{tabular}{|c|c|c|c|c|c|c|c|c|c|}
\hline \multirow[b]{2}{*}{ M-DQI component } & & \multicolumn{2}{|c|}{ Good (score 0-3)† } & \multicolumn{2}{|c|}{ Medium-good (score 4-7) } & \multicolumn{2}{|c|}{ Medium-poor (score 8-11) } & \multicolumn{2}{|c|}{ Poor (score 12-14)\| } \\
\hline & & Mean & SD & Mean & SD & Mean & SD & Mean & SD \\
\hline \multirow[t]{3}{*}{ SFA ( $\%$ of energy) } & Men & $9 \cdot 5^{a}$ & $1 \cdot 6$ & $11 \cdot 6^{b}$ & $2 \cdot 5$ & $13 \cdot 6^{c}$ & $2 \cdot 2$ & $15 \cdot 0^{d}$ & $1 \cdot 7$ \\
\hline & Women & $9 \cdot 8^{\mathrm{a}}$ & $1 \cdot 5$ & $12 \cdot 2^{b}$ & $2 \cdot 4$ & $14 \cdot 4^{\mathrm{C}}$ & $2 \cdot 1$ & $16 \cdot 1^{d}$ & $2 \cdot 0$ \\
\hline & All & $9 \cdot 7^{\mathrm{a}}$ & 1.5 & $12 \cdot 0^{\mathrm{b}}$ & $2 \cdot 5$ & $14 \cdot 1^{\mathrm{c}}$ & $2 \cdot 2$ & $15 \cdot 5^{d}$ & 1.9 \\
\hline \multirow[t]{3}{*}{ Cholesterol (mg) } & Men & $245 \cdot 2^{a}$ & $80 \cdot 3$ & $324 \cdot 2^{b}$ & $151 \cdot 8$ & $352 \cdot 3^{b}$ & $136 \cdot 2$ & $371 \cdot 2^{\mathrm{b}}$ & $81 \cdot 1$ \\
\hline & Women & $239 \cdot 7^{\mathrm{a}}$ & $67 \cdot 5$ & $288 \cdot 9^{a}$ & $104 \cdot 5$ & $341 \cdot 3^{b}$ & $136 \cdot 5$ & $378 \cdot 4^{\mathrm{b}}$ & $85 \cdot 9$ \\
\hline & All & $242 \cdot 0^{a}$ & $72 \cdot 6$ & $302 \cdot 1^{\mathrm{b}}$ & $125 \cdot 2$ & $345 \cdot 7^{\mathrm{C}}$ & $136 \cdot 1$ & $374 \cdot 8^{\mathrm{c}}$ & $81 \cdot 8$ \\
\hline \multirow[t]{3}{*}{ Olive oil (ml) } & Men & $26 \cdot 9^{a}$ & $11 \cdot 6$ & $25 \cdot 3^{a}$ & $13 \cdot 1$ & $18 \cdot 6^{\mathrm{b}}$ & $12 \cdot 4$ & $10 \cdot 2^{\mathrm{c}}$ & $6 \cdot 4$ \\
\hline & Women & $32 \cdot 0^{\mathrm{a}}$ & $9 \cdot 9$ & $24 \cdot 1^{\mathrm{b}}$ & $9 \cdot 6$ & $21 \cdot 9^{\mathrm{b}}$ & $10 \cdot 6$ & $5 \cdot 5^{c}$ & 3.6 \\
\hline & All & $29 \cdot 9^{a}$ & $10 \cdot 8$ & $24 \cdot 5^{b}$ & $11 \cdot 0$ & $20 \cdot 6^{c}$ & $11 \cdot 4$ & $7 \cdot 9^{d}$ & $5 \cdot 6$ \\
\hline \multirow[t]{3}{*}{ Fish (mg) } & Men & $91 \cdot 5^{\mathrm{a}}$ & $55 \cdot 7$ & $77 \cdot 8^{a, b}$ & $50 \cdot 9$ & $63 \cdot 7^{b}$ & $49 \cdot 3$ & $60 \cdot 3^{b}$ & $38 \cdot 7$ \\
\hline & Women & $98 \cdot 2^{\mathrm{a}}$ & $47 \cdot 9$ & $82 \cdot 8^{\mathrm{a}, \mathrm{b}}$ & $52 \cdot 4$ & $69 \cdot 7^{\mathrm{b}, \mathrm{c}}$ & $49 \cdot 0$ & $56 \cdot 8^{\mathrm{c}}$ & $47 \cdot 8$ \\
\hline & All & $95 \cdot 5^{a}$ & $51 \cdot 1$ & $80 \cdot 9^{\mathrm{a}, \mathrm{b}}$ & $51 \cdot 8$ & $67 \cdot 3^{b, c}$ & $49 \cdot 0$ & $58 \cdot 5^{\mathrm{c}}$ & $42 \cdot 6$ \\
\hline \multirow[t]{3}{*}{ Meat (mg) } & Men & $89 \cdot 7^{a}$ & $27 \cdot 5$ & $128 \cdot 9^{b}$ & 72.5 & $154 \cdot 4^{b}$ & $59 \cdot 6$ & $141 \cdot 3^{\mathrm{b}}$ & $35 \cdot 3$ \\
\hline & Women & $84 \cdot 3^{a}$ & $42 \cdot 3$ & $112 \cdot 8^{b}$ & $51 \cdot 2$ & $139 \cdot 5^{\mathrm{C}}$ & $61 \cdot 8$ & $172 \cdot 5^{\mathrm{d}}$ & $52 \cdot 4$ \\
\hline & All & $86 \cdot 5^{a}$ & $36 \cdot 9$ & $118 \cdot 8^{\mathrm{b}}$ & $60 \cdot 4$ & $145 \cdot 4^{\mathrm{C}}$ & $61 \cdot 2$ & $156 \cdot 9^{\mathrm{C}}$ & $46 \cdot 5$ \\
\hline \multirow[t]{3}{*}{$\mathrm{F} \& \mathrm{~V}(\mathrm{mg})$} & Men & $792 \cdot 3^{a}$ & $281 \cdot 0$ & $658 \cdot 9^{a, b}$ & $324 \cdot 2$ & $508 \cdot 1^{\mathrm{b}}$ & $346 \cdot 1$ & $334 \cdot 3^{\mathrm{c}}$ & $133 \cdot 4$ \\
\hline & Women & $727 \cdot 4^{a}$ & $254 \cdot 7$ & $659 \cdot 7^{\mathrm{a}, \mathrm{b}}$ & $256 \cdot 3$ & $567 \cdot 5^{\mathrm{b}}$ & $297 \cdot 0$ & $329 \cdot 7^{\mathrm{c}}$ & $232 \cdot 6$ \\
\hline & All & $786 \cdot 0^{\mathrm{a}}$ & $264 \cdot 4$ & $659 \cdot 4^{\mathrm{b}}$ & $282 \cdot 9$ & $543 \cdot 9^{\mathrm{C}}$ & $317 \cdot 8$ & $332 \cdot 0^{\mathrm{d}}$ & $185 \cdot 5$ \\
\hline \multirow[t]{3}{*}{ Cereals (mg) } & Men & $185 \cdot 2^{a}$ & $54 \cdot 0$ & $179 \cdot 9^{a}$ & 63.0 & $148 \cdot 0^{b}$ & 62.9 & $111 \cdot 0^{\mathrm{C}}$ & $47 \cdot 8$ \\
\hline & Women & $164 \cdot 3^{a}$ & $70 \cdot 4$ & $136 \cdot 5^{a, b}$ & $59 \cdot 6$ & $120 \cdot 9^{b}$ & $52 \cdot 2$ & $85 \cdot 5^{\mathrm{c}}$ & $42 \cdot 4$ \\
\hline & All & $172 \cdot 8^{a}$ & $64 \cdot 8$ & $152 \cdot 8^{a, b}$ & $64 \cdot 5$ & $131 \cdot 7^{\mathrm{C}}$ & $58 \cdot 0$ & $98 \cdot 2^{d}$ & $46 \cdot 1$ \\
\hline
\end{tabular}

F\&V, fruit and vegetables.

a,b,c,d Mean values within a row with unlike superscript letters were significantly different $(P<0 \cdot 05$, Duncan test). In all cases the $P$ value for the linear trend (two-factor ANOVA) was $<0.001$.

t $n_{\text {total }} 59(9.5 \%) ; n_{\text {men }} 25(9.6 \%) ; n_{\text {women }} 34(9.4 \%)$

$\ddagger n_{\text {total }} 339(54.6 \%) ; n_{\text {men }} 139(53.3 \%) ; n_{\text {women }} 200(55 \cdot 6 \%)$.

$\S n_{\text {total }} 212(34 \cdot 2 \%) ; n_{\text {men }} 93(35 \cdot 6 \%) ; n_{\text {women }} 119(33 \cdot 1 \%)$.

II $n_{\text {total }} 11(1 \cdot 7 \%) ; n_{\text {men }} 4(1.5 \%) ; n_{\text {women }} 7(1.9 \%)$. 
Table 4 Intake values (adjusted by energy) across the Mediterranean Diet Quality Index (M-DQI) categories according to sex among a representative sample ( $n 621$ ) from Catalonia, north-east Spain

\begin{tabular}{|c|c|c|c|c|c|c|c|c|c|c|}
\hline \multirow[b]{2}{*}{ Non M-DQI component } & & \multicolumn{2}{|c|}{ Good (score 0-3)† } & \multicolumn{2}{|c|}{ Medium-good (score 4-7) $\ddagger$} & \multicolumn{2}{|c|}{ Medium-poor (score 8-11) } & \multicolumn{2}{|c|}{ Poor (score 12-14)\| } & \multirow[b]{2}{*}{$P$ for trend } \\
\hline & & Mean & SD & Mean & SD & Mean & SD & Mean & SD & \\
\hline \multirow[t]{3}{*}{ Pulses (mg) } & Men & $17 \cdot 2$ & $11 \cdot 8$ & $19 \cdot 2$ & $14 \cdot 0$ & $17 \cdot 0$ & $12 \cdot 6$ & $14 \cdot 5$ & $11 \cdot 1$ & 0.541 \\
\hline & Women & $15 \cdot 6^{a}$ & $10 \cdot 5$ & $16 \cdot 7 a$ & $10 \cdot 4$ & $14 \cdot 5^{\mathrm{a}}$ & $10 \cdot 3$ & $7 \cdot 4^{\mathrm{b}}$ & 8.6 & 0.018 \\
\hline & All & $16 \cdot 2^{\mathrm{a}}$ & $11 \cdot 0$ & $17 \cdot 7^{\mathrm{a}}$ & 11.9 & $15 \cdot 5^{\mathrm{a}}$ & $11 \cdot 3$ & $10 \cdot 9^{\mathrm{b}}$ & $10 \cdot 3$ & 0.028 \\
\hline \multirow[t]{3}{*}{ Dairy productstt (mg) } & Men & $243 \cdot 3^{a}$ & $188 \cdot 3$ & $355 \cdot 7^{a, b}$ & $280 \cdot 5$ & $396 \cdot 2^{b}$ & 301.9 & $442 \cdot 3^{\mathrm{b}}$ & $248 \cdot 3$ & 0.018 \\
\hline & Women & $363 \cdot 1$ & $240 \cdot 0$ & $365 \cdot 1$ & $231 \cdot 3$ & $435 \cdot 0$ & $290 \cdot 5$ & $450 \cdot 7$ & $267 \cdot 9$ & $0 \cdot 126$ \\
\hline & All & $315 \cdot 2^{\mathrm{a}}$ & $227 \cdot 2$ & $361 \cdot 4^{\mathrm{a}, \mathrm{b}}$ & $250 \cdot 7$ & $419 \cdot 7^{\mathrm{a}, \mathrm{b}}$ & $295 \cdot 0$ & $446 \cdot 5^{\mathrm{b}}$ & 252.6 & 0.028 \\
\hline \multirow[t]{3}{*}{ Cheese (mg) } & Men & $21 \cdot 8$ & $18 \cdot 8$ & $37 \cdot 9$ & $39 \cdot 9$ & $38 \cdot 9$ & 41.5 & $26 \cdot 1$ & $16 \cdot 5$ & 0.058 \\
\hline & Women & $26 \cdot 7$ & $28 \cdot 1$ & $37 \cdot 1$ & $41 \cdot 3$ & 43.9 & $43 \cdot 4$ & $29 \cdot 1$ & $36 \cdot 5$ & 0.057 \\
\hline & All & $24 \cdot 7^{a}$ & $24 \cdot 8$ & $37 \cdot 4^{a, b}$ & $40 \cdot 7$ & $41.9^{\mathrm{b}}$ & $42 \cdot 6$ & $27 \cdot 6^{\mathrm{a}}$ & $27 \cdot 7$ & 0.003 \\
\hline \multirow[t]{3}{*}{ Pastries (mg) } & Men & $9 \cdot 3^{\mathrm{a}}$ & 9.8 & $28 \cdot 1^{\mathrm{a}}$ & $35 \cdot 2$ & $47 \cdot 4^{a, b}$ & $51 \cdot 1$ & $74 \cdot 9^{\mathrm{b}}$ & 62.2 & $<0.001$ \\
\hline & Women & $18 \cdot 0^{\mathrm{a}}$ & $18 \cdot 8$ & $25 \cdot 0^{\mathrm{a}}$ & $24 \cdot 4$ & $35 \cdot 1^{\mathrm{a}}$ & $32 \cdot 3$ & $62 \cdot 2^{b}$ & $72 \cdot 9$ & $<0.001$ \\
\hline & All & $14 \cdot 6^{a}$ & $16 \cdot 4$ & $26 \cdot 2^{a, b}$ & $29 \cdot 0$ & $40 \cdot 2^{b}$ & $41 \cdot 4$ & $66 \cdot 4^{c}$ & $65 \cdot 8$ & $<0.001$ \\
\hline \multirow[t]{3}{*}{ Alcoholic beverages (ml) } & Men & $227 \cdot 5$ & 348.5 & $227 \cdot 4$ & $272 \cdot 7$ & $237 \cdot 0$ & $290 \cdot 4$ & $226 \cdot 6$ & $199 \cdot 2$ & 0.997 \\
\hline & Women & 96.5 & $236 \cdot 6$ & $60 \cdot 4$ & 96.5 & $49 \cdot 1$ & $87 \cdot 0$ & $30 \cdot 0$ & $33 \cdot 7$ & $0 \cdot 175$ \\
\hline & All & 149.9 & $306 \cdot 4$ & $122 \cdot 9$ & $200 \cdot 0$ & $124 \cdot 2$ & $215 \cdot 6$ & $128 \cdot 3$ & $172 \cdot 1$ & 0.779 \\
\hline \multirow[t]{3}{*}{ Red wine (ml) } & Men & $110 \cdot 5^{\mathrm{a}}$ & $137 \cdot 5$ & $74 \cdot 2^{\mathrm{a}, \mathrm{b}}$ & $115 \cdot 7$ & $56 \cdot 0^{\mathrm{a}, \mathrm{b}}$ & $87 \cdot 0$ & $2 \cdot 8^{\mathrm{b}}$ & $4 \cdot 8$ & $0 \cdot 159$ \\
\hline & Women & $42 \cdot 4^{\mathrm{a}}$ & $66 \cdot 2$ & $25 \cdot 6^{a, b}$ & $61 \cdot 0$ & $13 \cdot 6^{a, b}$ & $36 \cdot 1$ & $1 \cdot 8^{\mathrm{b}}$ & $3 \cdot 3$ & 0.042 \\
\hline & All & $68 \cdot 8^{a}$ & $104 \cdot 2$ & $44 \cdot 3^{a, b}$ & $89 \cdot 2$ & $31 \cdot 2^{a, b}$ & $65 \cdot 7$ & $2 \cdot 1^{\mathrm{b}}$ & 3.6 & 0.016 \\
\hline
\end{tabular}

a,b,c Mean values within a row with unlike superscript letters were significantly different $(P<0 \cdot 05$, Duncan test).

$+n_{\text {total }} 59(9 \cdot 5 \%) ; n_{\text {men }} 25(9 \cdot 6 \%) ; n_{\text {women }} 34(9 \cdot 4 \%)$.

$\neq n_{\text {total }} 339(54.6 \%) ; n_{\text {men }} 139(53 \cdot 3 \%) ; n_{\text {women }} 200(55 \cdot 6 \%)$

$\$ n_{\text {total }} 212(34 \cdot 2 \%) ; n_{\text {men }} 93(35 \cdot 6 \%) ; n_{\text {women }} 119(33 \cdot 1 \%)$.

$\| n_{\text {total }} 11(1.7 \%) ; n_{\text {men }} 4(1.5 \%) ; n_{\text {women }} 7(1.9 \%)$.

Two-factor ANOVA.

tNot including cheese. 
consumption with one irregularity for the higher scores. However, there was no significant variation for cheese or total alcohol consumption across MDQ-I categories in both genders. Men and women with a higher adherence to the MD presented a significantly lower consumption of pastries, but a higher consumption of red wine.

Correlation coefficients with the M-DQI were calculated for the intake of macronutrients and some micronutrients (Table 5). Significant correlations were found for all macronutrients except for PUFA intake. Vitamins $\mathrm{B}_{12}, \mathrm{C}, \mathrm{E}$ and folic acid, and $\mathrm{Na}, \mathrm{Ca}, \mathrm{K}, \mathrm{Mg}$ and $\mathrm{Fe}$ were the vitamins and minerals significantly correlating with the M-DQI. The coefficients of correlations for the seven components of the index were all significant $(P<0 \cdot 001)$. In addition, pulses, cheese, pastries and red wine significantly correlated with the M-DQI, but not dairy products or alcoholic beverages. Generally, women had a higher consumption of SFA and dairy products, while men consumed more meat, cereals, pulses and alcoholic beverages.

From the FA profile, only stearic, oleic, linoleic and $\alpha$-linolenic acids, and arachidonic acid (AA), EPA and DHA correlated significantly with the M-DQI. Men showed a higher BMI and waist:hip ratio than women. Regarding biomarkers of CVD, the mean HDL-C concentration was higher in women than in men. In contrast, mean concentrations of LDL-C, TAG, glucose and both SPB and DBP were higher in men. Furthermore, only total cholesterol (TC), LDL-C, SBP and DBP correlated significantly with the M-DQI.

Gerber et al. used the amounts of EPA and DHA in erythrocytes as biomarkers of intake to validate the M$\mathrm{DQI}^{(25)}$. As expected, both FA decreased significantly as the M-DQI index range increased (Table 6). The same occurred with palmitic, oleic and $\alpha$-linolenic acids. Stearic, linoleic and $\mathrm{AA}$, as well as the $n-6: n-3$ ratio variation, increased significantly as the M-DQI index range increased - contrary to the aforementioned FA. No other significant changes were observed for the rest of the plasma FA profile.

In complementary correlation analyses, associations between foods and biomarkers were also examined. Oleic acid, $\alpha$-linolenic acid, EPA and DHA were found to be reliable biomarkers of protective foods such as olive oil, nuts and fish, respectively; while palmitic acid, stearic acid and AA were associated with less healthful foods such as meat (data not shown).

Table 7 shows the clinical biomarkers of disease across the M-DQI categories according to sex. All variables progressed with perfect regularity throughout the index ranges for both sexes, but for the majority of the markers, the change in the mean value was significant only for the extreme ranges of the MDQ-I (0-3 v. 12-14).

The curve for the distribution of subjects according to M-DQI value (Fig. 1) showed that the median M-DQI score was 7 for both genders; a total of $64 \%$ of subjects fell into the $0-7$ score range, $62 \%$ of them being female. Nearly $10 \%$ of both men and women presented the healthiest diet (scores 0-3), while 1.9\% of women and $1.5 \%$ of men showed the poorest diet (scores 12-14).

The mean M-DQI score was $6 \cdot 6$ (sD $2 \cdot 3$ ), showing nonsignificant differences between both genders (Table 8 ). The percentage of adherence to the MD was $53 \%$. According to age and for both genders, the older the subjects, the better M-DQI they had. The percentage of adherence to the MD was $45 \%, 51 \%, 57 \%$ and $60 \%$ for subjects aged $\leq 30$ years, 31-50 years, 51-65 years and $>65$ years, respectively. Subjects who had elevated BMI showed a higher M-DQI score than subjects with normal values, while subjects with elevated SBP/DBP presented a higher adherence to the MD. Non-smokers presented a higher adherence to the MD than did smokers. Moreover, rheumatoid arthritic patients had lower values of the M-DQI than non-rheumatoid arthritic subjects. No other significant differences were found for the remaining clinical characteristics considered in the analyses.

\section{Discussion}

The assessment of the quality of the MD in a coastal region from north-east Spain was evaluated by applying the M-DQI. The regular progression of the variables incorporated into the M-DQI across the scores, as well as their high and significant correlation coefficients, gave a coherent set of results. Moreover, we also examined the intake of other food groups of interest. Cheese, dairy products and pastries were considered because they were the main contributors to SFA intake in the Catalan diet ${ }^{(47)}$. This contribution justifies the significant positive correlation of cheese and pastries with the M-DQI. On the contrary, the lack of significance found in the correlation with dairy products could be explained by the fact that the negative effect of whole-fat milk and yoghurts on the M-DQI counteracted the positive effect of reduced-fat milk and yoghurt products. Pulses were also considered because the recent DAFNE (DAta Food Networking) databank study included pulses as a characteristic food group of the $\mathrm{MD}^{(48)}$, which may explain their negative correlation with the M-DQI. Alcoholic beverages neither progressed across the M-DQI categories nor correlated with the M-DQI. However, when alcohol sources were considered, subjects with a poor diet showed a significantly lower amount of red wine intake than subjects with a good diet. Besides, red wine intake correlated negatively with M-DQI. This reflects that drinking red wine is an integrated part of the MD.

The correlations of dietary energy and fat intake with diet indices were not always significant ${ }^{(20)}$. Consistent with the findings of others, our results showed that energy intake did not correlate with M-DQI, and correlation with macronutrients and micronutrients indicates healthful intakes for lower scores of the M-DQI ${ }^{(29,38)}$. For example, carotenoids, folic acid and vitamin $\mathrm{C}$ are 
Table 5 Daily intakes and correlation coefficients $(r)$ with Mediterranean Dietary Quality Index (M-DQI) score according to dietetic parameters and biomarkers among a representative sample ( $n$ 621) from Catalonia, north-east Spain

\begin{tabular}{|c|c|c|c|c|c|c|c|}
\hline & \multicolumn{2}{|c|}{ Men $(n$ 261) } & \multicolumn{2}{|c|}{ Women $(n$ 360) } & \multicolumn{2}{|c|}{ All $(n$ 621) } & \multirow[b]{2}{*}{$r$} \\
\hline & Mean & SD & Mean & SD & Mean & SD & \\
\hline Energy (kcal) & $2244 \cdot 2$ & $686 \cdot 2$ & $1981 \cdot 9^{* \star *}$ & $542 \cdot 7$ & $2092 \cdot 1$ & $603 \cdot 0$ & 0.045 \\
\hline Energy (MJ) & $9 \cdot 4$ & $2 \cdot 9$ & $8 \cdot 3^{\star \star *}$ & $2 \cdot 3$ & $8 \cdot 8$ & $2 \cdot 6$ & 0.045 \\
\hline Energy $(\mathrm{kJ} / \mathrm{kg})$ & $123 \cdot 1$ & $43 \cdot 0$ & $129 \cdot 3$ & $43 \cdot 5$ & $126 \cdot 7$ & $43 \cdot 3$ & 0.061 \\
\hline \multicolumn{8}{|l|}{ Macronutrients } \\
\hline Protein (\% of energy) & $18 \cdot 3$ & $3 \cdot 0$ & $18 \cdot 9^{*}$ & $3 \cdot 1$ & $18 \cdot 6$ & $3 \cdot 1$ & $0 \cdot 113^{\star \star}$ \\
\hline Animal protein (\% of energy) & $12 \cdot 5$ & $3 \cdot 2$ & $13 \cdot 5^{\star \star \star}$ & $3 \cdot 4$ & $13 \cdot 1$ & $3 \cdot 4$ & $0 \cdot 150^{\star \star \star}$ \\
\hline Vegetal protein ( $\%$ of energy) & $5 \cdot 8$ & $1 \cdot 1$ & $5 \cdot 4^{\star \star *}$ & $1 \cdot 1$ & $5 \cdot 6$ & $1 \cdot 1$ & $-0 \cdot 340^{* * *}$ \\
\hline $\mathrm{CHO}$ (\% of energy) & $44 \cdot 6$ & $6 \cdot 2$ & $42 \cdot 5^{\star \star \star}$ & $5 \cdot 7$ & $43 \cdot 4$ & $5 \cdot 9$ & $-0 \cdot 375^{\star \star *}$ \\
\hline Sugar ( $\%$ of energy) & $20 \cdot 4$ & $6 \cdot 2$ & $20 \cdot 6$ & $5 \cdot 5$ & $20 \cdot 5$ & $5 \cdot 8$ & $-0 \cdot 136^{* *}$ \\
\hline Complex $\mathrm{CHO}$ (\% of energy) & $24 \cdot 2$ & $5 \cdot \overline{7}$ & $22 \cdot 0^{\star \star \star}$ & $5 \cdot 5$ & $22 \cdot 9$ & $5 \cdot 6$ & $-0 \cdot 257^{\star \star \star}$ \\
\hline Fibre $(\mathrm{g})$ & $25 \cdot 4$ & $9 \cdot 0$ & $24 \cdot 0$ & $7 \cdot 6$ & $24 \cdot 6$ & $8 \cdot 2$ & $-0 \cdot 435^{\star \star \star}$ \\
\hline Total fat (\% of energy) & $37 \cdot 1$ & $6 \cdot 1$ & $38 \cdot 5^{\star \star *}$ & $5 \cdot 5$ & $37 \cdot 9$ & $5 \cdot 8$ & $0 \cdot 328^{\star * *}$ \\
\hline SFA ( $\%$ of energy) & $12 \cdot 0$ & $2 \cdot 7$ & $12 \cdot 6^{*}$ & $2 \cdot 8$ & $12 \cdot 3$ & $2 \cdot 8$ & $0 \cdot 528^{\star * *}$ \\
\hline MUFA (\% of energy) & $17 \cdot 4$ & $4 \cdot 1$ & $18 \cdot 5^{\star *}$ & $5 \cdot 5$ & $18 \cdot 0$ & 4.9 & $-0 \cdot 313^{\star * *}$ \\
\hline PUFA (\% of energy) & $7 \cdot 6$ & $2 \cdot 5$ & $7 \cdot 4$ & $2 \cdot 4$ & $7 \cdot 5$ & $2 \cdot 4$ & 0.064 \\
\hline \multicolumn{8}{|l|}{ Micronutrients } \\
\hline Cholesterol (mg) & $319 \cdot 5$ & $136 \cdot 8$ & $299 \cdot 0$ & $115 \cdot 7$ & $307 \cdot 6$ & $124 \cdot 6$ & $0.332^{\star \star \star}$ \\
\hline $\mathrm{Ca}(\mathrm{mg})$ & $1043 \cdot 1$ & $500 \cdot 7$ & $1044 \cdot 8$ & $425 \cdot 4$ & $1044 \cdot 1$ & $457 \cdot 0$ & $0 \cdot 115^{\star \star}$ \\
\hline $\mathrm{Na}(\mathrm{mg})$ & $4961 \cdot 8$ & 1748.5 & $4660 \cdot 4^{*}$ & $1635 \cdot 3$ & $4787 \cdot 1$ & $1682 \cdot 9$ & $-0.098^{\star}$ \\
\hline $\mathrm{K}(\mathrm{mg})$ & 3682.5 & $1244 \cdot 6$ & $3522 \cdot 4$ & $1027 \cdot 8$ & $3589 \cdot 7$ & $1118 \cdot 9$ & $-0 \cdot 140^{\star *}$ \\
\hline $\mathrm{Mg}(\mathrm{mg})$ & $391 \cdot 2$ & $23 \cdot 2$ & $367 \cdot 9^{\star}$ & $107 \cdot 1$ & $377 \cdot 1$ & $114 \cdot 2$ & $-0 \cdot 203^{* * *}$ \\
\hline $\mathrm{Zn}(\mathrm{mg})$ & $10 \cdot 3$ & $3 \cdot 7$ & $9 \cdot 7$ & 3.0 & $10 \cdot 0$ & $3 \cdot 3$ & 0.035 \\
\hline $\mathrm{P}(\mathrm{mg})$ & $1508 \cdot 7$ & $559 \cdot 2$ & $1442 \cdot 4$ & $456 \cdot 7$ & $1470 \cdot 3$ & $499 \cdot 8$ & 0.086 \\
\hline $\mathrm{Fe}(\mathrm{mg})$ & 14.5 & $4 \cdot 5$ & $13 \cdot 5^{\star \star \star}$ & $3 \cdot 8$ & $13 \cdot 9$ & $4 \cdot 1$ & $-0 \cdot 122^{\star *}$ \\
\hline Vitamin A $(\mu \mathrm{g})$ & $1237 \cdot 0$ & $818 \cdot 4$ & $1367 \cdot 0$ & $899 \cdot 1$ & $1312 \cdot 4$ & $865 \cdot 0$ & -0.036 \\
\hline Carotenoids $(\mu \mathrm{g})$ & $4785 \cdot 9$ & $3828 \cdot 1$ & $5522 \cdot 5^{*}$ & $4091 \cdot 9$ & $5212 \cdot 9$ & $3981 \cdot 0$ & $-0 \cdot 170^{\star * *}$ \\
\hline Vitamin $B_{1}(\mathrm{mg})$ & $1 \cdot 4$ & 0.5 & $1 \cdot 4$ & 0.4 & $1 \cdot 4$ & 0.4 & 0.012 \\
\hline Vitamin $B_{2}(\mathrm{mg})$ & $1 \cdot 8$ & $0 \cdot 8$ & $1 \cdot 8$ & $0 \cdot 7$ & $1 \cdot 8$ & $0 \cdot 7$ & 0.012 \\
\hline $\operatorname{Niacin}(\mathrm{mg})$ & $22 \cdot 2$ & $7 \cdot 8$ & $20 \cdot 5^{\star \star \star}$ & $6 \cdot 5$ & $21 \cdot 2$ & $7 \cdot 1$ & 0.031 \\
\hline Vitamin $\mathrm{B}_{6}(\mathrm{mg})$ & $2 \cdot 3$ & 0.9 & $2 \cdot 2^{\star}$ & $0 \cdot 7$ & $2 \cdot 2$ & $0 \cdot 7$ & -0.062 \\
\hline Folate $(\mu \mathrm{g})$ & $346 \cdot 4$ & $127 \cdot 6$ & $343 \cdot 1$ & 111.6 & $344 \cdot 4$ & $118 \cdot 0$ & $-0 \cdot 256^{\star \star \star}$ \\
\hline Vitamin $B_{12}(\mu \mathrm{g})$ & $8 \cdot 4$ & $4 \cdot 7$ & $7 \cdot 8$ & 4.5 & 8.0 & $4 \cdot 6$ & $0 \cdot 108^{*}$ \\
\hline Vitamin C (mg) & $167 \cdot 8$ & $88 \cdot 2$ & $175 \cdot 6$ & $76 \cdot 1$ & $172 \cdot 3$ & $81 \cdot 2$ & $-0 \cdot 301^{* * *}$ \\
\hline Vitamin D $(\mu \mathrm{g})$ & $3 \cdot 8$ & $2 \cdot 9$ & $3 \cdot 7$ & $2 \cdot 9$ & $3 \cdot 7$ & 2.9 & -0.085 \\
\hline Vitamin E $(\mu \mathrm{g})$ & $12 \cdot 9$ & $5 \cdot 6$ & $12 \cdot 6$ & $4 \cdot 9$ & $12 \cdot 7$ & $5 \cdot 2$ & $-0 \cdot 116^{\star *}$ \\
\hline \multicolumn{8}{|l|}{ Foods } \\
\hline Olive oil (ml) & $22 \cdot 6$ & $13 \cdot 0$ & $24 \cdot 1$ & $11 \cdot 1$ & $23 \cdot 5$ & 11.9 & $-0 \cdot 460^{\star \star * *}$ \\
\hline Fish (mg) & $75 \cdot 2$ & $51 \cdot 5$ & $80 \cdot 7$ & $51 \cdot 3$ & $78 \cdot 4$ & $51 \cdot 4$ & $-0 \cdot 494^{\star * *}$ \\
\hline Meat (mg) & $129 \cdot 6$ & $63 \cdot 6$ & $117 \cdot 8^{\star}$ & $57 \cdot 5$ & $122 \cdot 8$ & $60 \cdot 1$ & $0 \cdot 346^{\star \star \star}$ \\
\hline $\mathrm{F} \& \mathrm{~V}(\mathrm{mg})$ & $619 \cdot 8$ & $337 \cdot 2$ & $642 \cdot 2$ & $284 \cdot 4$ & $632 \cdot 8$ & $306 \cdot 6$ & $-0.600^{\star * *}$ \\
\hline Cereals (mg) & $166 \cdot 9$ & 63.8 & $135 \cdot 1^{\star \star \star}$ & $61 \cdot 6$ & $148 \cdot 5$ & 62.5 & $-0 \cdot 302^{\star \star *}$ \\
\hline Pulses (mg) & $17 \cdot 8$ & $13 \cdot 0$ & $15 \cdot 4^{\star}$ & $10 \cdot 5$ & $16 \cdot 4$ & $11 \cdot 6$ & $-0 \cdot 270^{\star \star \star}$ \\
\hline Dairy products $(\mathrm{mg})$ & 354.5 & $277 \cdot 0$ & $388 \cdot 5^{\star}$ & $255 \cdot 8$ & $374 \cdot 2$ & $264 \cdot 7$ & 0.019 \\
\hline Cheese (mg) & $34 \cdot 2$ & $36 \cdot 5$ & $36 \cdot 8$ & $39 \cdot 9$ & $35 \cdot 7$ & $38 \cdot 5$ & $0 \cdot 181^{\star *}$ \\
\hline Pastries (mg) & 34.0 & $42 \cdot 4$ & $28 \cdot 4$ & $29 \cdot 0$ & $30 \cdot 8$ & $34 \cdot 6$ & $0 \cdot 230^{\star \star *}$ \\
\hline Alcohol (ml) & $230 \cdot 4$ & $289 \cdot 9$ & $62 \cdot 6^{* \star *}$ & 142.5 & $133 \cdot 1$ & 204.5 & -0.027 \\
\hline Red wine (ml) & $70 \cdot 0$ & $108 \cdot 5$ & $22 \cdot 8^{\star \star \star}$ & $54 \cdot 5$ & $42 \cdot 6$ & $77 \cdot 2$ & $-0 \cdot 134^{\star *}$ \\
\hline \multicolumn{8}{|l|}{ Biomarkers of intaket } \\
\hline Stearic acid $(18: 0)$ & $6 \cdot 44$ & 0.93 & $6 \cdot 75^{\star \star \star}$ & $0 \cdot 74$ & $6 \cdot 62$ & $0 \cdot 82$ & $0.222^{* *}$ \\
\hline Oleic acid $(18: 1)$ & $25 \cdot 66$ & $5 \cdot 04$ & $23 \cdot 33^{\star \star \star}$ & $3 \cdot 78$ & $24 \cdot 31$ & $4 \cdot 31$ & $-0 \cdot 188^{\star}$ \\
\hline Linoleic acid $(18: 2 n-6)$ & $31 \cdot 19$ & $5 \cdot 90$ & $33.93^{\star \star *}$ & $4 \cdot 90$ & $33 \cdot 20$ & $5 \cdot 32$ & $0 \cdot 158^{\star}$ \\
\hline$\alpha$-Linolenic acid $(18: 3 n-3)$ & 0.32 & $0 \cdot 15$ & $0 \cdot 30^{\star *}$ & $0 \cdot 10$ & $0 \cdot 31$ & $0 \cdot 12$ & $-0 \cdot 230^{\star *}$ \\
\hline AA $(20: 4 n-6)$ & $6 \cdot 60$ & 1.57 & $7 \cdot 00^{\star \star}$ & $1 \cdot 38$ & $6 \cdot 83$ & $1 \cdot 46$ & $0.256^{\star \star}$ \\
\hline EPA $(20: 5 n-3)$ & 0.58 & 0.38 & 0.58 & $0 \cdot 36$ & 0.58 & $0 \cdot 37$ & $-0 \cdot 410^{* *}$ \\
\hline $\mathrm{DHA}(22: 6 n-3)$ & $2 \cdot 15$ & 0.74 & $2 \cdot 24$ & 0.53 & $2 \cdot 20$ & $0 \cdot 62$ & $-0 \cdot 360^{\star *}$ \\
\hline \multicolumn{8}{|l|}{ Biomarkers of CVD and obesity } \\
\hline BMI $\left(\mathrm{kg} / \mathrm{m}^{2}\right)$ & $27 \cdot 3$ & $4 \cdot 0$ & $25 \cdot 9^{\star \star}$ & $5 \cdot 2$ & $26 \cdot 5$ & $4 \cdot 7$ & 0.060 \\
\hline WHR & 0.92 & 0.07 & $0 \cdot 81^{\star * *}$ & 0.07 & $0 \cdot 86$ & 0.07 & 0.060 \\
\hline $\mathrm{SBP}(\mathrm{mmHg})$ & $129 \cdot 6$ & $18 \cdot 4$ & $123 \cdot 0^{\star \star \star *}$ & $21 \cdot 1$ & $125 \cdot 8$ & $20 \cdot 0$ & $0 \cdot 192^{\star \star \star}$ \\
\hline $\mathrm{DBP}(\mathrm{mmHg})$ & $81 \cdot 2$ & $10 \cdot 4$ & $78 \cdot 4^{\star \star *}$ & $10 \cdot 4$ & $79 \cdot 6$ & $10 \cdot 4$ & $0 \cdot 134^{\star \star *}$ \\
\hline $\mathrm{TC}(\mathrm{mmol} / \mathrm{l})$ & $5 \cdot 10$ & 0.93 & $5 \cdot 00$ & $1 \cdot 01$ & $5 \cdot 04$ & 0.98 & $0 \cdot 193^{\star \star \star}$ \\
\hline LDL-C $(\mathrm{mmol} / \mathrm{l})$ & $3 \cdot 25$ & 0.80 & $3 \cdot 04^{* *}$ & 0.90 & $3 \cdot 13$ & 0.87 & $0 \cdot 197^{\star \star \star}$ \\
\hline $\mathrm{HDL}-\mathrm{C}(\mathrm{mmol} / \mathrm{l})$ & $1 \cdot 21$ & 0.35 & $1 \cdot 46^{\star \star \star}$ & 0.36 & $1 \cdot 36$ & 0.36 & -0.059 \\
\hline $\mathrm{TAG}(\mathrm{mmol} / \mathrm{l})$ & $1 \cdot 34$ & 0.96 & $0.94^{\star \star \star}$ & 0.54 & $1 \cdot 11$ & 0.72 & 0.020 \\
\hline Glucose $(\mathrm{mmol} / \mathrm{l})$ & 5.94 & $1 \cdot 77$ & $5 \cdot 37^{\star \star \star}$ & $1 \cdot 07$ & $5 \cdot 61$ & $1 \cdot 36$ & 0.083 \\
\hline
\end{tabular}

$\mathrm{CHO}$, carbohydrate; F\&V, fruit and vegetables; AA, arachidonic acid; WHR, waist:hip ratio; SBP, systolic blood pressure; DBP, diastolic blood pressure; TC, total cholesterol; LDL-C, LDL cholesterol; HDL-C, HDL cholesterol.

Mean values were significantly different from those of men (one-way ANOVA) or significant $r$ value: ${ }^{\star} P<0 \cdot 05,{ }^{\star \star} P<0 \cdot 01,{ }^{\star \star \star} P<0 \cdot 001$.

tExpressed as percentage of total fatty acids; only those fatty acids that correlated with the M-DQI are shown. 
Table 6 Plasma fatty acid levels (percentage of total fatty acids) across the Mediterranean Diet Quality Index (M-DQI) categories among a representative sample $(n 621)$ from Catalonia, north-east Spain

\begin{tabular}{|c|c|c|c|c|c|c|c|c|}
\hline \multirow[b]{2}{*}{ Fatty acid } & \multicolumn{2}{|c|}{ Good (score 0-3)† } & \multicolumn{2}{|c|}{ Medium-good (score 4-7) $\ddagger$} & \multicolumn{2}{|c|}{ Medium-poor (score 8-11)§ } & \multicolumn{2}{|c|}{ Poor (score 12-14)| } \\
\hline & Mean & SD & Mean & SD & Mean & SD & Mean & SD \\
\hline $14: 0$ & $0.52^{a}$ & $0 \cdot 31$ & $0.63^{b}$ & $0 \cdot 32$ & $0.63^{b}$ & 0.42 & $0.64^{b}$ & 0.38 \\
\hline $16: 0$ & $20 \cdot 78^{a}$ & $2 \cdot 23$ & $20 \cdot 88^{a}$ & $2 \cdot 00$ & $19 \cdot 84^{\mathrm{b}}$ & 1.95 & $19 \cdot 66^{\mathrm{b}}$ & $1 \cdot 48$ \\
\hline $16: 1$ & $1 \cdot 65^{\mathrm{a}}$ & $0 \cdot 64$ & $1 \cdot 67^{\mathrm{a}}$ & 0.61 & $1 \cdot 68^{a}$ & $0 \cdot 60$ & $1 \cdot 46^{\mathrm{b}}$ & 0.53 \\
\hline $17: 0$ & 0.33 & 0.25 & 0.33 & 0.27 & 0.35 & 0.25 & 0.33 & 0.22 \\
\hline $18: 0$ - & $6 \cdot 38^{a}$ & 0.92 & $6 \cdot 58^{\mathrm{a}}$ & 0.72 & $6 \cdot 75^{\mathrm{b}}$ & 0.95 & $6 \cdot 77^{b}$ & 0.97 \\
\hline $18: 1^{1}$ & $25 \cdot 40^{\mathrm{a}}$ & $4 \cdot 47$ & $24 \cdot 48^{\mathrm{b}}$ & $4 \cdot 44$ & $23 \cdot 83^{c}$ & $4 \cdot 18$ & $22 \cdot 56^{d}$ & $2 \cdot 07$ \\
\hline $18: 2 n-6$ & $32 \cdot 20^{\mathrm{a}}$ & $5 \cdot 23$ & $32 \cdot 84^{\mathrm{a}}$ & $5 \cdot 62$ & $33 \cdot 91^{\mathrm{b}}$ & $5 \cdot 05$ & $35 \cdot 77^{\mathrm{C}}$ & 1.96 \\
\hline $18: 3 n-6$ & 0.43 & $0 \cdot 18$ & 0.42 & $0 \cdot 17$ & 0.40 & $0 \cdot 14$ & $0 \cdot 38$ & $0 \cdot 16$ \\
\hline $18: 3 n-3$ & $0 \cdot 34^{\mathrm{a}}$ & 0.13 & $0 \cdot 32^{a}$ & $0 \cdot 11$ & $0 \cdot 29^{b}$ & $0 \cdot 12$ & $0 \cdot 26^{c}$ & 0.11 \\
\hline $20: 0$ & $0 \cdot 11$ & 0.28 & $0 \cdot 12$ & 0.29 & $0 \cdot 13$ & 0.29 & 0.14 & $0 \cdot 15$ \\
\hline $20: 1$ & $0 \cdot 13$ & 0.09 & $0 \cdot 13$ & 0.07 & $0 \cdot 13$ & 0.07 & $0 \cdot 14$ & 0.02 \\
\hline $20: 2$ & $0 \cdot 20$ & $0 \cdot 17$ & $0 \cdot 21$ & 0.31 & $0 \cdot 21$ & $0 \cdot 16$ & 0.23 & 0.18 \\
\hline $20: 3 n-6$ & $1 \cdot 42$ & $0 \cdot 38$ & $1 \cdot 43$ & $0 \cdot 34$ & $1 \cdot 45$ & $0 \cdot 39$ & $1 \cdot 48$ & 0.40 \\
\hline $20: 4 n-6$ & $6 \cdot 37^{a}$ & $1 \cdot 44$ & $6 \cdot 58^{b}$ & 1.53 & $7 \cdot 34^{c}$ & $1 \cdot 40$ & $7 \cdot 44^{\mathrm{C}}$ & 0.84 \\
\hline $22: 0$ & 0.03 & 0.11 & 0.03 & 0.48 & 0.04 & $0 \cdot 16$ & 0.06 & $0 \cdot 19$ \\
\hline $24: 0$ & $0 \cdot 12$ & 0.07 & $0 \cdot 13$ & 0.29 & $0 \cdot 14$ & 0.09 & 0.14 & 0.08 \\
\hline $22: 5 n-6$ & $0 \cdot 36$ & 0.13 & 0.34 & $0 \cdot 12$ & 0.33 & $0 \cdot 11$ & 0.33 & 0.15 \\
\hline $20: 5 n-3$ & $0.75^{\mathrm{a}}$ & 0.36 & $0.58^{\mathrm{b}}$ & 0.40 & $0.53^{\mathrm{c}}$ & 0.33 & $0 \cdot 36^{d}$ & 0.31 \\
\hline $22: 6 n-3$ & $2 \cdot 45^{a}$ & 0.53 & $2 \cdot 29^{b}$ & 0.62 & $2 \cdot 01^{\mathrm{c}}$ & 0.63 & $1 \cdot 83^{d}$ & 0.79 \\
\hline$n-6: n-3$ & $11 \cdot 5^{\mathrm{a}}$ & $4 \cdot 00$ & $13 \cdot 8^{\mathrm{b}}$ & $5 \cdot 00$ & $14 \cdot 1^{\mathrm{b}}$ & 4.53 & $18 \cdot 5^{\mathrm{c}}$ & $5 \cdot 90$ \\
\hline
\end{tabular}

a,b,c,d Mean values within a row with unlike superscript letters were significantly different $(P<0 \cdot 05$, Duncan test).

t $n_{\text {total }} 59(9 \cdot 5 \%) ; n_{\text {men }} 25(9 \cdot 6 \%) ; n_{\text {women }} 34(9 \cdot 4 \%)$.

$\ddagger n_{\text {total }} 339(54.6 \%) ; n_{\text {men }} 139(53.3 \%) ; n_{\text {women }} 200$ (55.6\%).

$\S n_{\text {total }} 212(34 \cdot 2 \%) ; n_{\text {men }} 93(35 \cdot 6 \%) ; n_{\text {women }} 119(33 \cdot 1 \%)$

$\| n_{\text {total }} 11(1.7 \%) ; n_{\text {men }} 4(1.5 \%) ; n_{\text {women }} 7(1.9 \%)$.

The unique fatty acids for which $P$ for trend was $<0.05$ (one-way ANOVA).

Table 7 Clinical markers across the Mediterranean Diet Quality Index (M-DQI) categories according to sex among a representative sample ( $n$ 621) from Catalonia, north-east Spain

\begin{tabular}{|c|c|c|c|c|c|c|c|c|c|c|}
\hline \multirow[b]{2}{*}{ Clinical marker } & & \multicolumn{2}{|c|}{$\begin{array}{c}\text { Good } \\
\text { (score 0-3)† }\end{array}$} & \multicolumn{2}{|c|}{$\begin{array}{c}\text { Medium-good } \\
\text { (score 4-7) }\end{array}$} & \multicolumn{2}{|c|}{$\begin{array}{l}\text { Medium-poor } \\
\text { (score 8-11)§ }\end{array}$} & \multicolumn{2}{|c|}{$\begin{array}{c}\text { Poor } \\
\text { (score 12-14)\| }\end{array}$} & \multirow[b]{2}{*}{$P$ for trend $\Phi$} \\
\hline & & Mean & SD & Mean & SD & Mean & SD & Mean & SD & \\
\hline \multirow[t]{2}{*}{ BMI $\left(\mathrm{kg} / \mathrm{m}^{2}\right)$} & Men & $25 \cdot 2^{a}$ & $2 \cdot 2$ & $27 \cdot 2^{b}$ & $2 \cdot 1$ & $28 \cdot 2^{\mathrm{b}}$ & $2 \cdot 3$ & $28 \cdot 8^{\mathrm{b}}$ & $2 \cdot 2$ & 0.336 \\
\hline & Women & $23 \cdot 6^{\mathrm{a}}$ & $2 \cdot 0$ & $26 \cdot 0^{\mathrm{b}}$ & $2 \cdot 2$ & $26 \cdot 6^{\mathrm{b}}$ & 1.9 & $26 \cdot 7^{\mathrm{b}}$ & $2 \cdot 3$ & 0.458 \\
\hline \multirow[t]{2}{*}{ WHR } & Men & $0 \cdot 87^{a}$ & 0.02 & $0.90^{\mathrm{a}}$ & 0.03 & $0.92^{\mathrm{a}}$ & 0.03 & $1 \cdot 00^{b}$ & 0.05 & 0.053 \\
\hline & Women & $0.77^{\mathrm{a}}$ & 0.03 & $0 \cdot 81^{\mathrm{a}}$ & 0.04 & $0.82^{a}$ & 0.04 & $0 \cdot 87^{b}$ & 0.05 & 0.125 \\
\hline \multirow[t]{2}{*}{$\mathrm{SBP}(\mathrm{mmHg})$} & Men & $118 \cdot 2^{\mathrm{a}}$ & $10 \cdot 4$ & $129 \cdot 3^{\mathrm{b}}$ & $13 \cdot 2$ & $132 \cdot 2^{b}$ & $12 \cdot 3$ & $141 \cdot 4^{\mathrm{C}}$ & $15 \cdot 1$ & 0.005 \\
\hline & Women & $114 \cdot 9^{\mathrm{a}}$ & $11 \cdot 0$ & $120 \cdot 8^{\mathrm{b}}$ & $10 \cdot 8$ & $127 \cdot 9^{c}$ & $12 \cdot 5$ & $138 \cdot 9^{d}$ & $12 \cdot 2$ & 0.002 \\
\hline \multirow[t]{2}{*}{$\mathrm{DBP}(\mathrm{mmHg})$} & Men & $78 \cdot 3^{a}$ & $7 \cdot 3$ & $80 \cdot 5^{a}$ & $7 \cdot 2$ & $82 \cdot 8^{a}$ & $7 \cdot 5$ & $86 \cdot 6^{\mathrm{b}}$ & $7 \cdot 4$ & $0 \cdot 164$ \\
\hline & Women & $71 \cdot 5^{a}$ & $7 \cdot 1$ & $78 \cdot 3^{b}$ & $7 \cdot 4$ & $80 \cdot 2^{b}$ & $7 \cdot 3$ & $83 \cdot 7^{c}$ & $7 \cdot 5$ & 0.009 \\
\hline \multirow{2}{*}{ TC $(\mathrm{mmol} / \mathrm{l})$} & Men & $4 \cdot 51^{\mathrm{a}}$ & 0.68 & $5 \cdot 01^{a}$ & 0.90 & $5 \cdot 13^{\mathrm{a}}$ & 0.96 & $5 \cdot 35^{b}$ & 0.93 & 0.037 \\
\hline & Women & $4 \cdot 37^{\mathrm{a}}$ & 1.05 & $4 \cdot 79^{\mathrm{a}, \mathrm{b}}$ & 1.04 & $5 \cdot 10^{b}$ & 0.98 & $5 \cdot 26^{b}$ & 0.98 & 0.021 \\
\hline \multirow{2}{*}{ LDL-C (mmol/l) } & Men & $2 \cdot 85^{\mathrm{a}}$ & 0.69 & $3 \cdot 15^{a, b}$ & 0.75 & $3 \cdot 30^{b}$ & $0 \cdot 82$ & $3 \cdot 43^{b}$ & 0.85 & 0.039 \\
\hline & Women & $2 \cdot 27^{\mathrm{a}}$ & 0.72 & $2 \cdot 89^{\mathrm{a}}$ & 0.90 & $3 \cdot 11^{a}$ & 0.90 & $3 \cdot 35^{\mathrm{b}}$ & 0.87 & 0.008 \\
\hline \multirow[t]{2}{*}{$\mathrm{HDL}-\mathrm{C}(\mathrm{mmol} / \mathrm{l})$} & Men & $1 \cdot 26^{a}$ & 0.09 & $1 \cdot 22^{a}$ & $0 \cdot 10$ & $1 \cdot 16^{a}$ & $0 \cdot 10$ & $1 \cdot 02^{b}$ & $0 \cdot 11$ & $0 \cdot 122$ \\
\hline & Women & $1 \cdot 48^{\mathrm{a}}$ & $0 \cdot 10$ & $1 \cdot 46^{\mathrm{a}}$ & $0 \cdot 12$ & $1 \cdot 46^{\mathrm{a}}$ & $0 \cdot 12$ & $1 \cdot 26^{b}$ & 0.11 & 0.847 \\
\hline \multirow[t]{2}{*}{ TAG (mmol/l) } & Men & $1 \cdot 25^{a}$ & $0 \cdot 11$ & $1 \cdot 36^{b}$ & $0 \cdot 11$ & $1 \cdot 34^{\mathrm{b}}$ & $0 \cdot 11$ & $1 \cdot 37^{b}$ & $0 \cdot 11$ & 0.460 \\
\hline & Women & $0.88^{\mathrm{a}}$ & 0.09 & $0.93^{\mathrm{a}}$ & 0.09 & $0.98^{b}$ & 0.09 & $1 \cdot 06^{b}$ & 0.09 & 0.216 \\
\hline \multirow[t]{2}{*}{ Glucose $(\mathrm{mmol} / \mathrm{l})$} & Men & $5 \cdot 14^{\mathrm{a}}$ & 0.56 & $5 \cdot 81^{\mathrm{b}}$ & $1 \cdot 52$ & $6 \cdot 12^{b}$ & 1.95 & $6 \cdot 05^{b}$ & 1.92 & 0.283 \\
\hline & Women & $5 \cdot 19$ & 0.93 & $5 \cdot 31$ & 0.95 & $5 \cdot 35$ & $1 \cdot 23$ & $5 \cdot 56$ & $1 \cdot 16$ & 0.455 \\
\hline
\end{tabular}

WHR, waist:hip ratio; SBP, systolic blood pressure; DBP, diastolic blood pressure; TC, total cholesterol; LDL-C, LDL cholesterol; HDL-C, HDL cholesterol. a,b,c,d Mean values within a row with unlike superscript letters were significantly different $(P<0 \cdot 05$, Duncan test).

t $n_{\text {total }} 59(9.5 \%) ; n_{\text {men }} 25(9.6 \%) ; n_{\text {women }} 34(9 \cdot 4 \%)$.

$\ddagger n_{\text {total }} 339(54 \cdot 6 \%) ; n_{\text {men }} 139(53 \cdot 3 \%) ; n_{\text {women }} 200(55 \cdot 6 \%)$.

$\S n_{\text {total }} 212(34 \cdot 2 \%) ; n_{\text {men }} 93(35 \cdot 6 \%) ; n_{\text {women }} 119(33 \cdot 1 \%)$.

$\| n_{\text {total }} 11(1.7 \%) ; n_{\text {men }} 4(1.5 \%) ; n_{\text {women }} 7(1.9 \%)$.

TTwo-factor ANOVA.

regarded as micronutrients associated with healthful foods such as $F \& V$, giving rise to negative correlation coefficients with the M-DQI. Conversely, vitamin $B_{12}$ is associated with less healthful foods such as meat and dairy products, which is the reason for the positive correlation observed with the M-DQI. The correlation coefficients were similar to or even higher than other reported values ${ }^{(29,38)}$. 


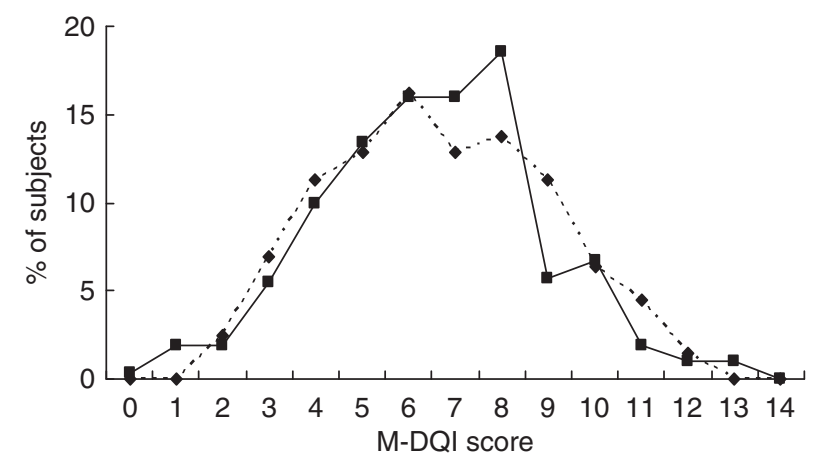

Fig. 1 Distribution of subjects (- - - - - -, men; - $\mathbf{\square -}$, women) according to score of the Mediterranean Diet Quality Index (M-DQI) among a population-based random sample ( $n$ 621) derived from the Catalan Nutrition Survey, Spain

With all this in mind, the components that were and were not included in the index showed that the M-DQI was successful in providing an overall assessment of food habits in Catalonia according to the MDP. Moreover, this adequacy was supported by the validation using biomarkers of nutrition intake. Biomarkers of protective foods correlated directly with a higher adherence to the MDP, while biomarkers of less healthful foods correlated inversely with a higher MDP adherence.

Palmitic and stearic acids have been associated with increased risk of $\mathrm{CHD}^{(49)}$. As expected, participants with a lower MDP adherence had significantly higher plasma concentrations of stearic acid. Although palmitic acid was inversely related to the M-DQI, this finding agrees with the fact that a low-fat diet leads to a significant increase in palmitic acid incorporated in plasma phospholipids ${ }^{(50)}$. Neuhouser et al. also reported this tendency for both saturated $\mathrm{FA}^{(30)}$.

The fact that olive oil is the largest contributor of total fat (70\%) among the Catalan population ${ }^{(47)}$ and $92 \%$ of the MUFA present in foods is oleic acid (60-80\% of oleic acid intake coming from olive oil ${ }^{(51)}$ ) could be an explanation for its increasing content observed in our study across the M-DQI categories. Fish and nut intakes, for which beneficial effects on human health have been reported ${ }^{(52-54)}$, are also characteristic of the Catalan population and could explain the increasing EPA, DHA and $\alpha$-linolenic acid contents throughout the M-DQI categories.

Both EPA and DHA presented significant negative correlations with the M-DQI. Similar to our findings, Gerber et al. found a significant correlation between the DQI adapted for the French Mediterranean diet and marine $\mathrm{FA}^{(25)}$. Conversely, Neuhouser et al. found no associations of EPA and DHA with the DQI ${ }^{(30)}$. The variations in fish consumption patterns between subjects in Mediterranean regions and subjects in a Western region are likely to explain these observed differences.

Because both $n-6$ and $n$-3 PUFA are associated with a lower risk of $\mathrm{CHD}^{(55)}$, the ratio is only weakly related to CHD risk ${ }^{(55,56)}$. Nevertheless, it is generally accepted that the ratio of $n-6$ to $n-3$ in Western diets (20-30:1) is less than optimal and should be improved to approach recommendations $(4-5: 1)^{(57)}$. As expected, the present study showed a gradual decrease of the $n-6: n-3$ ratio in participants with a better adherence to the MD. However, although the $n-6: n-3$ ratio of the subjects with a better adherence to the MD is lower than that of Western diets, it is still far from the recommendations.

In the present study, we also analysed the M-DQI in relation to clinical biomarkers. A significant inverse association was found between MDP adherence and TC and LDL-C levels, but not HDL-C. These findings are in agreement with Newby et al. and Panagiotakos et al., who found that TC was negatively correlated with the DQI revised and the MD score, respectively ${ }^{(29,35)}$; and with Álvarez-León et al., who found no association between MD scores and HDL-C in a Canarian population $^{(34)}$. Furthermore, although Sofi et al. observed no influence of adherence to the MD on blood lipid levels, the addition of lifestyle habits to the MD score resulted in a significant association between scores and TC, LDL-C and $\mathrm{TAG}^{(36)}$. However, in several other studies opposite results have been found ${ }^{(25,31-33)}$. These differences could be due to different dietary patterns among populations as well as to the different indices used. For example, Kant and Graubard found different results when three different indices were applied to the same population ${ }^{(31)}$.

Consistent with our findings, several studies found that adherence to dietary patterns was inversely associated with $\mathrm{BP}^{(31,32,34,35)}$, but not with $\mathrm{TAG}^{(29,31,33,34)}$ or glucose $\mathrm{e}^{(32,36)}$. The strong correlation between the M-DQI and $\mathrm{BP}$ could be due to the variables included in the M-DQI, which approximate those of an 'ideal' dietary pattern to reduce $\mathrm{BP}^{(58)}$.

No consistent associations have been identified between dietary patterns and BMI, discrepancies being attributable to differences in control of confounders or in the dietary assessment methods ${ }^{(59)}$. Thus, several studies have reported that adherence to the MD is inversely associated with $\mathrm{BMI}^{(8,31,32,35,60)}$, while others have found no association ${ }^{(36,38,61,62)}$. In the present study, subjects with a normal BMI presented a higher adherence to the MDP than those being overweight or obese. However, BMI did not differ significantly across the M-DQI categories. This fact could be due to the cross-sectional nature of the study. Thus, obese subjects could be following physicians' advice of increasing their adherence to a healthy dietary pattern. Moreover, obese people tend to under-report energy intake and overestimate the intake of healthy foods, resulting in lower scores. The large proportion of overweight and obese participants in our study could lead to an underestimation of the association between BMI and M-DQI.

The Catalan sample presented a mean M-DQI score of 6.6 (SD 2.3) and 53\% adherence to the MDP, which is at the borderline value of classification for good adherence 
Table 8 Mediterranean Diet Quality Index (M-DQI) scores according to sex and age among a representative sample $(n$ 621) from Catalonia, north-east Spain

\begin{tabular}{|c|c|c|c|c|c|c|c|c|c|c|c|c|c|c|c|c|}
\hline \multirow[b]{3}{*}{ Clinical characteristic } & \multicolumn{4}{|c|}{ Sex } & \multicolumn{8}{|c|}{ Age } & \multirow[b]{3}{*}{$P$ for trendt $t$} & & & \multirow[b]{3}{*}{$P \neq$} \\
\hline & \multicolumn{2}{|c|}{ Men ( $n$ 261) } & \multicolumn{2}{|c|}{ Women (n 360) } & \multicolumn{2}{|c|}{$\leq 30$ years $(n 107)$} & \multicolumn{2}{|c|}{$31-50$ years $(n 246)$} & \multicolumn{2}{|c|}{$51-65$ years $(n 177)$} & \multicolumn{2}{|c|}{$>65$ years $(n 91)$} & & \multicolumn{2}{|c|}{ All $(n$ 621) } & \\
\hline & Mean & SD & Mean & SD & Mean & SD & Mean & SD & Mean & SD & Mean & SD & & Mean & $\overline{S D}$ & \\
\hline All subjects & $6 \cdot 7$ & $2 \cdot 3$ & $6 \cdot 5$ & $2 \cdot 3$ & $7 \cdot 7^{\mathrm{a}}$ & $2 \cdot 2$ & $6 \cdot 8^{b}$ & $2 \cdot 2$ & $6 \cdot 0^{c}$ & $2 \cdot 3$ & $5 \cdot 6^{c}$ & $2 \cdot 3$ & $<0.001$ & $6 \cdot 6$ & $2 \cdot 3$ & \\
\hline \multicolumn{17}{|l|}{ Anthropometric characteristics } \\
\hline Normal (n 268) & $6 \cdot 4$ & $2 \cdot 3$ & $6 \cdot 2$ & $2 \cdot 3$ & $7 \cdot 6^{a}$ & $2 \cdot 1$ & $6 \cdot 7^{\mathrm{b}}$ & $2 \cdot 3$ & $6 \cdot 2^{b}$ & $2 \cdot 3$ & $5 \cdot 3^{c}$ & $2 \cdot 0$ & $<0.001$ & $6 \cdot 3$ & $2 \cdot 3$ & 0.015 \\
\hline Elevated $(n 353) \S$ & $7 \cdot 2$ & $2 \cdot 4$ & $6 \cdot 8$ & $2 \cdot 3$ & $7 \cdot 7^{\mathrm{a}}$ & $2 \cdot 4$ & $6 \cdot 8^{a}$ & $2 \cdot 0$ & $7 \cdot 0^{\mathrm{a}}$ & 3.0 & $5 \cdot 5^{\mathrm{b}}$ & $2 \cdot 4$ & $<0.001$ & $6 \cdot 9$ & $2 \cdot 4$ & \\
\hline \multicolumn{17}{|l|}{ WHR } \\
\hline Normal ( $n$ 548) & $6 \cdot 8$ & $1 \cdot 7$ & $6 \cdot 2$ & $2 \cdot 8$ & $7 \cdot 2$ & $2 \cdot 3$ & $6 \cdot 9$ & $2 \cdot 2$ & $6 \cdot 9$ & $2 \cdot 1$ & $5 \cdot 6$ & $2 \cdot 7$ & 0.245 & $6 \cdot 4$ & $2 \cdot 4$ & 0.735 \\
\hline Elevated $(n 73) \|$ & $6 \cdot 7$ & $2 \cdot 5$ & $6 \cdot 5$ & $2 \cdot 3$ & $7 \cdot 7^{\mathrm{a}}$ & $2 \cdot 3$ & $6 \cdot 9^{b}$ & $2 \cdot 2$ & $5 \cdot 7^{\mathrm{c}}$ & $2 \cdot 3$ & $5 \cdot 7^{\mathrm{c}}$ & $2 \cdot 2$ & $<0.001$ & $6 \cdot 6$ & $2 \cdot 4$ & \\
\hline \multirow{2}{*}{\multicolumn{17}{|c|}{ CVD risk factors }} \\
\hline & & & & & & & & & & & & & & & & \\
\hline Normal (n 415) & $6 \cdot 5$ & $2 \cdot 4$ & $6 \cdot 4$ & $2 \cdot 4$ & $7 \cdot 7^{\mathrm{a}}$ & $2 \cdot 2$ & $6 \cdot 7^{\mathrm{b}}$ & $2 \cdot 2$ & $5 \cdot 9^{c}$ & $2 \cdot 3$ & $5 \cdot 2^{c}$ & $2 \cdot 5$ & $<0.001$ & $6 \cdot 5$ & $2 \cdot 4$ & 0.271 \\
\hline Low $(n 206)+t$ & $7 \cdot 0$ & $2 \cdot 4$ & $6 \cdot 5$ & $2 \cdot 2$ & $7 \cdot 5^{\mathrm{a}}$ & $2 \cdot \overline{4}$ & $6 \cdot 9^{\mathrm{a}, \mathrm{b}}$ & $2 \cdot 1$ & $6 \cdot 2^{b}$ & $2 \cdot 5$ & $6 \cdot 2^{\mathrm{b}}$ & $1 \cdot 9$ & 0.033 & $6 \cdot 7$ & $2 \cdot 3$ & \\
\hline \multicolumn{17}{|l|}{ TAG } \\
\hline Normal (n 535) & $6 \cdot 5$ & $2 \cdot 5$ & $5 \cdot 8$ & $2 \cdot 0$ & $6 \cdot 3$ & 1.5 & $6 \cdot 9$ & $2 \cdot 5$ & $5 \cdot 8$ & $2 \cdot 2$ & $5 \cdot 9$ & $2 \cdot 6$ & $0 \cdot 340$ & $6 \cdot 3$ & $2 \cdot 3$ & 0.274 \\
\hline Elevated $(n 86) \ddagger \ddagger$ & $6 \cdot 7$ & $2 \cdot 3$ & $6 \cdot 5$ & $2 \cdot 4$ & $7 \cdot 7^{\mathrm{a}}$ & $2 \cdot 2$ & $6 \cdot 8^{\mathrm{b}}$ & $2 \cdot 2$ & $6 \cdot 0^{\mathrm{c}}$ & $2 \cdot 4$ & $5 \cdot 5^{\mathrm{c}}$ & $2 \cdot 3$ & $<0.001$ & $6 \cdot 6$ & $2 \cdot 4$ & \\
\hline \multicolumn{17}{|l|}{ Glucose } \\
\hline Normal (n 399) & $6 \cdot 5$ & $2 \cdot 2$ & $6 \cdot 3$ & $2 \cdot 2$ & $7 \cdot 2$ & $2 \cdot 0$ & $6 \cdot 7$ & $2 \cdot 1$ & $6 \cdot 1$ & $2 \cdot 2$ & $6 \cdot 0$ & $2 \cdot 3$ & 0.567 & $6 \cdot 4$ & $2 \cdot 2$ & 0.209 \\
\hline Elevated (n 222)§§ & $6 \cdot 8$ & $2 \cdot 5$ & $6 \cdot 5$ & $2 \cdot 4$ & $7 \cdot 8^{\mathrm{a}}$ & $2 \cdot 3$ & $6 \cdot 8^{\mathrm{b}}$ & $2 \cdot 2$ & $5 \cdot 9^{c}$ & $2 \cdot 4$ & $5 \cdot 0^{\mathrm{c}}$ & $2 \cdot 2$ & $<0.001$ & $6 \cdot 6$ & $2 \cdot 4$ & \\
\hline \multicolumn{17}{|l|}{ SBP/DBP } \\
\hline Normal (n 258) & $7 \cdot 3$ & $2 \cdot 4$ & $6 \cdot 7$ & $2 \cdot 1$ & $7 \cdot 6$ & 1.9 & $7 \cdot 0$ & $2 \cdot 3$ & $6 \cdot 1$ & $2 \cdot 0$ & $6 \cdot 3$ & $3 \cdot 2$ & 0.015 & $6 \cdot 9$ & $2 \cdot 2$ & 0.003 \\
\hline Elevated ( $n$ 363) IIII & $6 \cdot 4$ & $2 \cdot 3$ & $6 \cdot 2$ & $2 \cdot 5$ & $7 \cdot 9^{\mathrm{a}}$ & $2 \cdot 4$ & $6 \cdot 4^{b}$ & $2 \cdot 0$ & $5 \cdot 8^{\mathrm{b}, \mathrm{c}}$ & $2 \cdot 5$ & $5 \cdot 6^{\mathrm{c}}$ & $2 \cdot 2$ & $<0.001$ & $6 \cdot 3$ & $2 \cdot 4$ & \\
\hline \multicolumn{17}{|l|}{ Smoker } \\
\hline No (n 422) & $6 \cdot 4$ & $2 \cdot 4$ & $6 \cdot 2$ & $2 \cdot 3$ & $7 \cdot 6^{\mathrm{a}}$ & $2 \cdot 4$ & $6 \cdot 5^{\mathrm{b}}$ & $2 \cdot 1$ & $5 \cdot 9^{\mathrm{b}, \mathrm{c}}$ & $2 \cdot 4$ & $5 \cdot 4^{c}$ & $2 \cdot 3$ & $<0.001$ & $6 \cdot 3$ & $2 \cdot 3$ & $<0.001$ \\
\hline Yes $(n 199)$ & $7 \cdot 2$ & $2 \cdot 3$ & $7 \cdot 1$ & $2 \cdot 3$ & $7 \cdot 7$ & $2 \cdot 1$ & $7 \cdot 2$ & $2 \cdot 4$ & $6 \cdot 4$ & $2 \cdot 4$ & $6 \cdot 6$ & $1 \cdot 8$ & 0.056 & $7 \cdot 1$ & $2 \cdot 3$ & \\
\hline \multicolumn{17}{|l|}{ Diagnosed pathologies } \\
\hline \multicolumn{17}{|l|}{ Depression/anxiety } \\
\hline No $(n 514)$ & $6 \cdot 7$ & $2 \cdot 3$ & $6 \cdot 5$ & $2 \cdot 4$ & $7 \cdot 7^{\mathrm{a}}$ & $2 \cdot 3$ & $6 \cdot 9^{b}$ & $2 \cdot 2$ & $5 \cdot 9^{c}$ & $2 \cdot 3$ & $5 \cdot 5^{\mathrm{c}}$ & $2 \cdot 3$ & $<0.001$ & $6 \cdot 6$ & $2 \cdot 4$ & 0.508 \\
\hline Yes $(n 107)$ & $6 \cdot 7$ & $2 \cdot 7$ & $6 \cdot 3$ & $2 \cdot 1$ & $7 \cdot 2$ & $1 \cdot 2$ & $6 \cdot 4$ & $2 \cdot \overline{2}$ & $6 \cdot 3$ & $2 \cdot 5$ & $6 \cdot 3$ & $2 \cdot 5$ & 0.858 & $6 \cdot 4$ & $2 \cdot 3$ & \\
\hline \multicolumn{17}{|l|}{ Rheumatoid arthritis } \\
\hline No $(n$ 471) & $6 \cdot 8$ & $2 \cdot 3$ & $6 \cdot 6$ & $2 \cdot 3$ & $7 \cdot 7^{\mathrm{a}}$ & $2 \cdot 3$ & $6 \cdot 8^{\mathrm{b}}$ & $2 \cdot 2$ & $6 \cdot 0^{c}$ & $2 \cdot 3$ & $5 \cdot 7^{c}$ & $2 \cdot 1$ & $<0.001$ & $6 \cdot 7$ & $2 \cdot 3$ & 0.003 \\
\hline Yes $(n 150)$ & $5 \cdot 8$ & $2 \cdot 4$ & $6 \cdot 0$ & $2 \cdot 3$ & $7 \cdot 8^{\mathrm{a}}$ & $1 \cdot 3$ & $6 \cdot 6^{a, b}$ & $2 \cdot 2$ & $6 \cdot 0^{\mathrm{a}, \mathrm{b}}$ & $2 \cdot 4$ & $5 \cdot 5^{\mathrm{b}}$ & $2 \cdot 4$ & $0 \cdot 137$ & $6 \cdot 0$ & $2 \cdot 0$ & \\
\hline
\end{tabular}

WHR, waist:hip ratio; HDL-C, HDL cholesterol; SBP, systolic blood pressure; DBP, diastolic blood pressure.

${ }_{a, b, c}$ Mean values within a row with unlike superscript letters were significantly different $(P<0.05$, Duncan test)

t $P$ value for linear trend according to age (two-factor ANOVA).

$\ddagger P$ value among groups within every clinical characteristic (one-way ANOVA).

$\S \mathrm{BMI} \geq 25 \mathrm{~kg} / \mathrm{m}^{2}$

WHR $>1.00$ in men; WHR $>0.90$ in women.

Involved in the International Diabetes Federation definition of the metabolic syndrome (2005), with the exception of smokers.

$\mathrm{ttHDL}-\mathrm{C}<1.0 \mathrm{mmol} / \mathrm{l}$ in men; HDL-C $<1.3 \mathrm{mmol} / \mathrm{l}$ in women

$\pm T A G \geq 1.7 \mathrm{mmol} /$

Fasting plasma glucose $>5.6 \mathrm{mmol} / \mathrm{l}$ or previously diagnosed type 2 diabetes.

$\top$ Only those pathologies pertaining to more than $15 \%$ of the Catalan sample were considered. 
to the MD (score $\leq 7$, adherence $\geq 50 \%)^{(25)}$. Our results suggest that although the current Catalan population still follows the MDP, it is being lost, mainly in the younger generations. This trend has also been reported in other Mediterranean regions ${ }^{(44,63-65)}$. Taking into account that childhood obesity is unfortunately one of the pandemics of the 21 st century ${ }^{(66)}$, young age groups of the population should be a priority target for nutrition interventions to prevent obesity and diet-related diseases.

The fact that hypertensive and rheumatoid arthritic patients showed M-DQI values lower than non-hypertensive and non-rheumatoid arthritic subjects could also be explained by the cross-sectional design of the study. So, patients may have adopted a healthier diet, as has been observed in previous studies ${ }^{(44)}$. For example, in the Catalan sample, patients suffering from these pathologies showed a significantly higher intake of olive oil than the rest of the subjects.

The main limitation of our study is its cross-sectional nature. Therefore, we cannot establish causal relationships but only generate hypotheses for the associations between diseases and biomarkers. Because of the large proportion of overweight and obese participants, underreporting of energy intake and overestimated intake of 'healthy' foods may give rise to lower scores. Moreover, not all components of the M-DQI (i.e. F\&V or cereals) are represented by our intake biomarkers.

However, the current investigation also has several strengths. First, we used a validated FFQ previously applied to other Spanish populations ${ }^{(42-44)}$. Second, we employed an elevated number of biomarkers to confirm data obtained from the FFQ, because they are independent of participant's memory and social factors.

In conclusion, the M-DQI has been demonstrated a suitable tool for measuring adequately the diet quality of the Catalan population since it correlates with intake of several macro- and micronutrients, and is supported by the regular progression of nutritional biomarkers across the scores. Recent data have shown reduced CVD risk factors ${ }^{(67-69)}$, mortality ${ }^{(2)}$ and prevalence of obesity ${ }^{(8)}$ in people adhering to a MD. Consistent with these findings, significant associations between the M-DQI and some biomarkers of disease have been found, revealing that this index may have potential applications for clinical purposes as a predictor of groups at risk. The study also indicates that although the Catalan population still follows the traditional MD habits, they are disappearing, especially among young subjects, who appear to be a group at risk and the primary target for promotion of the MDP.

\section{Acknowledgements}

The study was supported by Mercadona SA and is part of the studies carried out by the Xarxa Temàtica en Nutrició (Generalitat de Catalunya) and the Centre Català de la
Nutrició de Institut d'Estudis Catalans in relation to the Health Survey of Catalonia, ESCA 2002-2003. The research reported in the article was not funded by any of the listed funding bodies. There are no conflicts of interest. I.B.-P. and J.M.-P. contributed equally and share first authorship of the paper. All of the authors (I.B.-P., J.M.-P., L.S.-M., A.I.C., A.M. and M.C.L.-S.) contributed in the design, analysis and interpretation of data of the manuscript. The authors are grateful to the Public Health Division of the Department of Health of the Autonomous Government of Catalonia for providing the blood samples for the study. Special thanks to Mr Lindsey Moshell for the manuscript correction; and to the Spanish Ministry of Education for their PhD grant to I.B.-P.

\section{References}

1. Serra-Majem L, Ngo de la Cruz J, Ribas L \& Tur JA (2003) Olive oil and the Mediterranean diet: beyond the rhetoric. Eur J Clin Nutr 57, Suppl. 1, S2-S7.

2. Trichopoulou A (2004) Traditional Mediterranean diet and longevity in the elderly: a review. Public Health Nutr 7 , 943-947.

3. Sanchez-Villegas A, Bes-Rastrollo M, Martinez-Gonzalez MA \& Serra-Majem L (2006) Adherence to a Mediterranean dietary pattern and weight gain in a follow-up study: the SUN cohort. Int J Obes (Lond) 30, 350-358.

4. Estruch R, Martínez-González MA, Corella D et al. (2006) Effects of a Mediterranean-style diet on cardiovascular risk factors: a randomized trial. Ann Intern Med 145, 1-11.

5. Bondia-Pons I, Schröder H, Covas MI, Castellote AI, Kaikkonen J, Poulsen HE, Gaddi AV, Machowetz A, Kiesewetter H \& López-Sabater MC (2007) A moderate consumption of olive oil in European healthy men reduced the systolic blood pressure in non-Mediterranean participants. J Nutr 137, 84-87.

6. Trichopoulou A \& Dilis V (2007) Olive oil and longevity. Mol Nutr Food Res 51, 1275-1278.

7. Fitó M, Guxens M, Corella D et al. (2007) Effect of a traditional Mediterranean diet on lipoprotein oxidation: a randomized controlled trial. Arch Intern Med 167, 1195-1203.

8. Panagiotakos DB, Chrysohoou C, Pitsavos C \& Stefanadis C (2006) Association between the prevalence of obesity and adherence to the Mediterranean diet: the ATTICA study. Nutrition 22, 449-456.

9. Dai J. Miller AH, Bremner JD et al. (2008) Adherence to the Mediterranean diet is inversely associated with circulating interleukin-6 among middle-aged men: a twin study. Circulation 117, 169-175.

10. Giugliano D, Ceriello A \& Esposito K (2008) Are there specific treatments for the metabolic syndrome? Am J Clin Nutr 87, 8-11.

11. Knoops KT, de Groot LC, Fidanza F, Alberti-Fidanza A, Kromhout D \& van Staveren W (2006) Comparison of three different dietary scores in relation to 10 -year mortality in elderly European subjects: the HALE project. Eur J Clin Nutr 60, 746-755.

12. Harriss LR, English DR, Powles J, Giles GG, Tonkin AM, Hodge AM, Brazionis L \& O'Dea K (2007) Dietary patterns and cardiovascular mortality in the Melbourne Collaborative Cohort Study. Am J Clin Nutr 86, 221-229.

13. Mitrou PN, Kipnis V, Thiébaut AC et al. (2007) Mediterranean dietary pattern and prediction of all-cause mortality in a US population: results from the NIH-AARP Diet and Health Study. Arch Intern Med 167, 2461-2468. 
14. Serra-Majem L, Roman B \& Estruch R (2006) Scientific evidences of interventions using the Mediterranean diet: a systematic review. Nutr Rev 64, 2 Pt 2, S27-S47.

15. Lairon D (2007) Intervention studies on Mediterranean diet and cardiovascular risk. Mol Nutr Food Res 51, 1209-1214.

16. Willett WC, Sacks F, Trichopoulou A, Drescher G, FerroLuzzi A, Helsing E \& Trichopoulos D (1995) Mediterranean diet pyramid: a cultural model for healthy eating. Am J Clin Nutr 61, Suppl. 6, S1402-S1406.

17. Garcia-Closas R, Berenguer A \& González CA (2006) Changes in food supply in Mediterranean countries from 1961 to 2001. Public Health Nutr 9, 53-60.

18. Balanza R, García-Lorda P, Pérez-Rodrigo C, Aranceta J, Bonet MB \& Salas-Salvadó J (2007) Trends in food availability determined by the Food and Agriculture Organization's food balance sheets in Mediterranean Europe in comparison with other European areas. Public Health Nutr 10, 168-176.

19. Chen Q \& Marques-Vidal P (2007) Trends in food availability in Portugal in 1966-2003: comparison with other Mediterranean countries. Eur J Nutr 46, 418-427.

20. Kant AK (2004) Dietary patterns and health outcomes. J Am Diet Assoc 104, 615-635.

21. Trichopoulos D \& Lagiou P (2004) Mediterranean diet and overall mortality differences in the European Union. Public Health Nutr 7, 949-951.

22. Bach A, Serra-Majem L, Carrasco JL, Roman B, Ngo J, Bertomeu I \& Obrador B (2006) The use of indexes evaluating the adherence to the Mediterranean diet in epidemiological studies: a review. Public Health Nutr 9, 132-146.

23. Waijers PM, Feskens EJ \& Ocké MC (2007) A critical review of predefined diet quality scores. Br J Nutr 97, 219-231.

24. Arvaniti F \& Panagiotakos DB (2008) Healthy indexes in public health practice and research: a review. Crit Rev Food Sci Nutr 48, 317-327.

25. Gerber MJ, Scali JD, Michaud A, Durand MD, Astre CM, Dallongeville J \& Romon MM (2000) Profiles of a healthful diet and its relationship to biomarkers in a population sample from Mediterranean southern France. I Am Diet Assoc 100, 1164-1171.

26. Patterson RE, Haines PS \& Popkin BM (1994) Diet Quality Index: capturing a multidimensional behaviour. I Am Diet Assoc 94, 57-64.

27. Bingham SA (2002) Biomarkers in nutritional epidemiology. Public Health Nutr 5, 821-827.

28. Hann CS, Rock CL, King I \& Drewnowski A (2001) Validation of Healthy Eating Index with use of plasma biomarkers in a clinical sample of women. Am J Clin Nutr 74, 479-486.

29. Newby PK, Hu FB, Rimm EB et al. (2003) Reproducibility and validity of the Diet Quality Index Revised as assessed by use of a food-frequency questionnaire. Am J Clin Nutr 78, 941-949.

30. Neuhouser ML, Patterson RE, King IB, Horner NK \& Lampe JW (2003) Selected nutritional biomarkers predict diet quality. Public Health Nutr 6, 703-709.

31. Kant AK \& Graubard BI (2005) A comparison of three dietary pattern indexes for predicting biomarkers of diet and disease. J Am Coll Nutr 24, 294-303.

32. Pitsavos C, Panagiotakos DB, Tzima N et al. (2005) Adherence to the Mediterranean diet is associated with total antioxidant capacity in healthy adults: the ATTICA study. Am J Clin Nutr 82, 694-699.

33. Bach-Faig A, Geleva D, Carrasco JL, Ribas-Barba L \& SerraMajem L (2006) Evaluating associations between Mediterranean diet adherence indexes and biomarkers of diet and disease. Public Health Nutr 9, 1110-1117.

34. Álvarez-León EE, Henríquez P \& Serra-Majem L (2006) Mediterranean diet and metabolic syndrome: a cross- sectional study in the Canary Islands. Public Health Nutr 9, 1089-1098.

35. Panagiotakos DB, Pitsavos C \& Stefanadis C (2006) Dietary patterns: a Mediterranean diet score and its relation to clinical and biological markers of cardiovascular disease risk. Nutr Metab Cardiovasc Dis 16, 559-568.

36. Sofi F, Gori AM, Marcucci R, Innocenti G, Dini C, Genise S, Abbate R, Surrenti C \& Casini A (2007) Adherence to a healthful life attenuates lipid parameters among a healthy Italian population. Nutr Metab Cardiovasc Dis 17, 642-648.

37. Scali J, Richard A \& Gerber M (2001) Diet profiles in a population sample from Mediterranean southern France. Public Health Nutr 4, 173-182.

38. Satalic Z, Baric IC, Keser I \& Maric B (2004) Evaluation of diet quality with the Mediterranean dietary quality index in university students. Int J Food Sci Nutr 55, 589-597.

39. Juncà S, Guillén M, Aragay JM, Brugulat P, Castell C, Séculi E, Medina A \& Tresserras R (2003) Methodological aspects in the evaluation of health and risk-reduction objectives of Health Plan for Catalonia for the year 2000. Med Clin (Barc) 121, Suppl. 1, 10-19.

40. Goldberg GR, Black AE, Jebb SA, Cole TJ, Murgatroyd PR, Coward WA \& Prentice AM (1991) Critical evaluation of energy intake data using fundamental principles of energy physiology: 1 . Derivation of cut-off limits to identify underrecording. Eur J Clin Nutr 45, 569-581.

41. Alberti KG, Zimmet P \& Shaw J (2005) The metabolic syndrome: a new worldwide definition. Lancet 366 , 1059-1062.

42. Martin-Moreno JM, Boyle P, Gorgojo L, Maisonneuve P, Fernandez-Rodriguez JC, Salvini S \& Willett WC (1993) Development and validation of a food frequency questionnaire in Spain. Int J Epidemiol 22, 512-519.

43. Serra-Majem L, Armas-Navarro A \& Ribas-Barba L, on behalf of the Research Group ENCA (1997-98) (1999) Nutritional Survey of Canary Islands: Dietary Habits and Food Consumption. Report no. 1. Santa Cruz de Tenerife: ENCA Research Group.

44. Tur JA, Romaguera D \& Pons A (2004) Adherence to the Mediterranean dietary pattern among the population of the Balearic Islands. Br J Nutr 92, 341-346.

45. Cervera P (2006) Food Composition Tables of CESNID (The Centre for Superior Studies in Nutrition and Dietetics). Barcelona: McGraw-Hill.

46. Bondia-Pons I, Castellote AI \& López-Sabater MC (2004) Comparison of conventional and fast gas chromatography in human plasma fatty acid determination. J Chromatogr $B$ Analyt Technol Biomed Life Sci 809, 339-344.

47. Bondia-Pons I, Serra-Majem L, Castellote AI \& LópezSabater MC (2007) Identification of foods contributing to the dietary lipid profile of a Mediterranean population. $\mathrm{BrJ}$ Nutr 98, 583-592.

48. Naska A, Fouskakis D, Oikonomou E et al. (2006) Dietary patterns and their socio-demographic determinants in 10 European countries: data from the DAFNE databank. EurJ Clin Nutr 60, 181-190.

49. Hu FB, Manson JE \& Willett WC (2001) Types of dietary fat and coronary heart disease: a critical review. J Am Coll Nutr 20, 5-19.

50. Raatz SK, Bibus D, Thomas W \& Kris-Etherton P (1999) Total fat intake modifies fatty acid composition in humans. J Nutr 131, 231-234.

51. Pérez-Jimenez F, López-Miranda J \& Mata P (2002) Protective effect of dietary monounsaturated fat on arteriosclerosis: beyond cholesterol. Atherosclerosis 163, 385-398.

52. Harris WS, Miller M, Tighe AP, Davidson MH \& Schaefer EJ (2008) Omega-3 fatty acids and coronary heart disease risk: clinical and mechanistic perspectives. Atherosclerosis 197, $12-24$. 
53. Ros E \& Mataix J (2006) Fatty acid composition of nuts implications for cardiovascular health. BrJ Nutr 96, Suppl. 2, S29-S35.

54. Marangoni F, Colombo C, Martiello A, Poli A, Paoletti R \& Galli C (2007) Levels of the $n$-3 fatty acid eicosapentaenoic acid in addition to those of $\alpha$ linolenic acid are significantly raised in blood lipids by the intake of four walnuts a day in humans. Nutr Metab Cardiovasc Dis 17, 457-461.

55. Wijendran V \& Hayes KC (2004) Dietary $n-6$ and $n-3$ fatty acid balance and cardiovascular health. Annu Rev Nutr 24, 597-615.

56. Griffin BA (2008) How relevant is the ratio of dietary $n-6$ to $n-3$ polyunsaturated fatty acids to cardiovascular disease risk? Evidence from the OPTILIP study. Curr Opin Lipidol 19, 57-62.

57. Gebauer SK, Psota TL, Harris WS \& Kris-Etherton PM (2006) $n-3$ Fatty acids dietary recommendations and food sources to achieve essentiality and cardiovascular benefits. $\mathrm{Am} \mathrm{J}$ Clin Nutr 83, Suppl. 6, S1526-S1535.

58. Sacks FM, Obarzanek E, Windhauser MM et al. (1995) Rationale and design of the Dietary Approaches to Stop Hypertension trial (DASH). A multicenter controlled-feeding study of dietary patterns to lower blood pressure. Ann Epidemiol 5, 108-118.

59. Togo P, Osler M, Sorensen TI \& Heitmann BL (2001) Food intake patterns and body mass index in observational studies. Int J Obes Relat Metab Disord 25, 1741-1751.

60. Schröder H, Marrugat J, Vila J, Covas MI \& Elosua R (2004) Adherence to the traditional Mediterranean diet is inversely associated with body mass index and obesity in a Spanish population. J Nutr 134, 3355-3361.

61. Trichopoulou A, Naska A, Orfanos P \& Trichopoulos D (2005) Mediterranean diet in relation to body mass index and waist-to-hip ratio: the Greek European Prospective Investigation into Cancer and Nutrition Study. Am J Clin Nutr 82, 935-940.
62. Rossi M, Negri E, Bosetti C et al. (2008) Mediterranean diet in relation to body mass index and waist-to-hip ratio. Public Health Nutr 11, 214-217.

63. Serra-Majem L, Trichopoulou A, Ngo de la Cruz J, Cervera P, García Alvarez A, La Vecchia C, Lemtouni A \& Trichopoulos D (2004) Does the definition of the Mediterranean diet need to be updated? Public Health Nutr 7 , 927-929.

64. Kontogianni MD, Vidra N, Farmaki AE et al. (2008) Adherence rates to the Mediterranean diet are low in a representative sample of Greek children and adolescents. J Nutr 138, 1951-1956.

65. Baldini M, Pasqui F, Bordoni A \& Maranesi M (2009) Is the Mediterranean lifestyle still a reality? Evaluation of food consumption and energy expenditure in Italian and Spanish university students. Public Health Nutr 12, 148-155.

66. Malecka-Tendera E \& Mazur A (2006) Childhood obesity: a pandemic of the twenty-first century. Int J Obes (Lond) 30, Suppl. 2, S1-S3.

67. Vincent-Baudry S, Defoort C, Gerber M et al. (2005) The Medi-RIVAGE study: reduction of cardiovascular disease risk factors after a 3-mo intervention with a Mediterranean-type diet or a low-fat diet. Am J Clin Nutr 82, 964-971.

68. Ambring A, Johansson M, Axelsen M, Gan L, Strandvik B \& Friberg P (2006) Mediterranean-inspired diet lowers the ratio of serum phospholipid $n-6$ to $n-3$ fatty acids, the number of leukocytes and platelets, and vascular endothelial growth factor in healthy subjects. Am J Clin Nutr 83, 575-581.

69. Alonso A, Beunza JJ, Delgado-Rodríguez M, Martinez JA \& Martínez-González MA (2006) Low-fat dairy consumption and reduced risk of hypertension: the Seguimiento Universidad de Navarra (SUN) cohort. Am J Clin Nutr 82, 972-979. 